\title{
Transcript Profile in Vegetable Soybean Roots Reveals Potential Gene Patterns Regulating K Uptake Efficiency
}

\author{
Changkai Liu ${ }^{1,2}\left(\mathbb{D}\right.$, Bingjie Tu ${ }^{1,2}$, Xue Wang ${ }^{1,3,4}$, Yansheng Li ${ }^{1}$, Qiuying Zhang ${ }^{2,3, *}$ and \\ Xiaobing Liu ${ }^{1}$ (D) \\ 1 Key Laboratory of Mollisols Agroecology, Northeast Institute of Geography and Agroecology, CAS, \\ Harbin 150081, China; liuchangkai@iga.ac.cn (C.L.); tubingjie17@mails.ucas.edu.cn (B.T.); \\ wangxue16@mails.ucas.edu.cn (X.W.); liyansheng@iga.ac.cn (Y.L.); liuxb@iga.ac.cn (X.L.) \\ 2 Innovation Academy for Seed Design, Chinese Academy of Sciences, Harbin 150081, China \\ 3 Key Laboratory of Soybean Molecular Breeding, Northeast Institute of Geography and Agroecology, \\ Chinese Academy of Sciences, Harbin 150081, China \\ 4 University of the Chinese Academy of Sciences, Beijing 100049, China \\ * Correspondence: zhangqiuying@iga.ac.cn; Tel.: +86-451-86601320; Fax: +86-451-86603720
}

Received: 26 October 2020; Accepted: 12 November 2020; Published: 16 November 2020

\begin{abstract}
Significant differences have been reported in root $\mathrm{K}^{+}$uptake between high potassium efficiency (HKE) and low potassium efficiency (LKE) in vegetable soybean genotypes. The ideal morphological and physiological characteristics of HKE have been defined. However, the mechanism by which HKE vegetable soybean genotypes efficiently uptake $\mathrm{K}$ remains unclear. By using representative materials, this study investigated the responses of root development to low K (LK) stress, and identified and assessed the key genes affecting high-efficiency K uptake between HKE and LKE vegetable soybean roots. The root growth of LKE was significantly inhibited under the LK condition. Compared with LKE, HKE had more lateral roots in both LK and CK (control) conditions. Lateral root of HKE was more preferentially responsive to exogenous IAA, with a wider response threshold to IAA concentration (from 0.1 to $1 \mu \mathrm{M}$ ). Transcriptome analysis revealed that LK induced transport-related genes up-regulated in HKE compared with LKE. In HKE, homologous genes of a K channel encoding gene potassium channel AKT1 (AKT1) and a K transporter gene high-affinity $\mathrm{K}^{+}$ transporter 5 (HAK5) were both highly expressed under the LK stress. Additionally, genes related to plant hormones signal transductions were also identified differentially expressed between the two genotypes. Plant hormone signaling involved in root morphological regulation pathways may play significant roles in improving the efficiency of vegetable soybean $\mathrm{K}^{+}$uptake. A diagram showing possible molecular mechanisms in regulating root high-efficiency uptake $\mathrm{K}^{+}$in vegetable soybean is proposed.
\end{abstract}

Keywords: potassium high-efficiency; RNA-Seq; root architecture; lateral root; vegetable soybean

\section{Introduction}

Potassium $(\mathrm{K})$ is one of the most important mineral nutrients, and is essential for crop yield and quality [1]. Cultivars with high efficiency of uptake and use of $\mathrm{K}$ nutrient are widely used to reduce the use of chemicals in agriculture [2], and are thus an effective way of reducing $\mathrm{K}$ fertilizer cost [3]. Vegetable soybean (Glycine max (L.) Merrill) is a crop with a high K demand [4]. Based on the selection of highly efficient $\mathrm{K}$ uptake and use associated with specific morphological and physiological characteristics, representative high $\mathrm{K}$ efficiency vegetable soybean genotypes have been identified that have efficient dry matter and $\mathrm{K}$ redistribution ability and high specific root uptake $\mathrm{K}$ ability $[5,6]$. 
To achieve specific research objectives and improve the breeding efficiency, it is necessary to study the representative materials in depth and popularize them with respect to general research and application. However, the internal mechanism by which high $\mathrm{K}$ efficiency genotypes efficiently uptake $\mathrm{K}^{+}$is still unclear. Understanding the potassium uptake mechanism is of great significance for the development of $\mathrm{K}$-efficient and low $\mathrm{K}^{+}$tolerant cultivars, and has thus attracted extensive attention [7].

The mechanism of potassium uptake by plant roots and of the loading and transport within plants has been the focus of many studies [8-10]. The uptake and transport of $\mathrm{K}^{+}$in plants are mainly completed by high-affinity $\left(\mathrm{K}^{+}\right.$transporters) and low-affinity $\left(\mathrm{K}^{+}\right.$channels) transport systems belonging to different protein families [11]. In the model plant Arabidopsis thaliana, many $\mathrm{K}^{+}$channels and transporters have been identified, and a clear demonstration of the physiological roles of the proteins involved has been made [11]. Potassium channels and transporters can be categorized into six different gene families, consisting of three channel families (Shaker, TPK, and Kir-like families) and three transporter families (KUP/HAK/KT, HKT, and CPA families) $[8,12]$. When the external $\mathrm{K}^{+}$ concentrations are below $0.01 \mathrm{mM}$, the proton-driven $\mathrm{H}^{+} / \mathrm{K}^{+}$co-transporter AtHAK5 is the only system responsible for $\mathrm{K}^{+}$uptake from the soil. Meanwhile, for $\mathrm{K}^{+}$concentrations between $0.01 \mathrm{mM}$ and $0.05 \mathrm{mM}, \mathrm{AtHAK} 5$ and AKT1 together contribute to $\mathrm{K}^{+}$uptake. At higher external $\mathrm{K}^{+}$concentrations, AKT1, together with other low-affinity $\mathrm{K}^{+}$uptake systems, is responsible for $\mathrm{K}^{+}$uptake from the soil [13-15]. In Arabidopsis, the SKOR channel, a member of the Shaker family, is expressed in the root stele, where it contributes to $\mathrm{K}^{+}$secretion into the xylem sap toward the shoots [16].

Root uptake of $\mathrm{K}$ also greatly depends on root architecture development [17], especially lateral root formation [18]. Plants with more lateral roots can absorb more water and nutrients from external environments [19,20]. Furthermore, plant phytohormones always play important roles in root architecture establishment [21]. For instance, an auxin source in lateral root cap (LRC) cells can influence the LRP/LR initiation sites via the auxin influx carrier member encoded by the AUX1 gene [22].

Expression of specific $\mathrm{K}$ transport proteins induced by $\mathrm{K}$ starvation is regulated by the form of gene regulation network $[20,23,24]$. For instance, as one of the most important members of the Shaker family, AKT1 function is activated through phosphorylation, which is mediated by CBL (calcineurin B-like protein)-interacting protein kinases (CIPKs) [25]. Some phytohormones, kinases, and transcript factors can play regulatory or signal transduction roles in $\mathrm{K}$ uptake $[7,26]$. The specific patterns of given plant species in responding to potassium starvation stress are linked to their growth strategy. These responses, under the condition of low potassium, depend on tissues and genotypes as well [27]. For instance, when Arabidopsis is under K starvation, transcript levels for the Jasmonic Acid (JA) biosynthetic enzymes including lipoxygenase, allene oxide synthase, and allene oxide cyclase strongly increase, but they quickly decrease after $\mathrm{K}^{+}$resupply [28] (Armengaud et al., 2004). These highlight a novel role of JA in nutrient signaling and stress management through a variety of physiological processes such as nutrient storage, recycling, and reallocation [28].

Transcriptome profiling is a critical method for unveiling the gene regulation mechanism and for elucidating the response mechanism to a specific environmental stimulus [29,30]. Whole transcriptome analyses have been performed using RNA-Seq to examine genes involved in abiotic stress under many conditions $[28,31,32]$. By using the RNA-Seq technique, a series of potential genes responsible for drought-tolerance in Asian pears were found [33], the gene expression patterns of pear leaves and fruit in response to different $\mathrm{K}$ levels were investigated [34], and the transcript levels of different $\mathrm{K}$ efficiency in watermelon roots were analyzed [7]. This paper examined the root transcriptome profile associated with morphological and physiological characteristics under $\mathrm{K}$ starvation for representative high/low K efficiency vegetable soybeans. The purpose of this study was to understand the potential mechanism by which high $\mathrm{K}$ efficiency vegetable soybean roots efficiently uptake $\mathrm{K}^{+}$from the soil environment. The results of this study will provide an important basis in accelerating the breeding processes for high K efficiency vegetable soybean. 


\section{Materials and Methods}

\subsection{Selection of Plant Materials and Growth Conditions}

The two vegetable soybean genotypes used in the study, Line 20 (low K tolerant) and Line 7 (low $\mathrm{K}$ sensitive), were based on our previous investigation of forty vegetable soybean varieties (lines) in Harbin, Northeast China $\left(45^{\circ} 73^{\prime} \mathrm{N}, 126^{\circ} 61^{\prime} \mathrm{E}\right.$, and altitude $\left.128 \mathrm{~m}\right)[5,6]$. These two materials are very representative genotypes in terms of potassium uptake and use, as well as morphological and physiological characteristics. Vegetable soybean seeds were sterilized and germinated on moistened filter paper in a plant growth chamber at $60 \%$ humidity and $28{ }^{\circ} \mathrm{C}$, under a $16 / 8 \mathrm{~h}$ (light/dark) cycle for 3-4 days. After that, the seedlings were transferred into light-tight glass boxes with $1 / 2$ strength modified Hoagland nutrient solution described by Wang et al. (2012) [26]. The solution was composed of $2 \mathrm{mM} \mathrm{Ca}\left(\mathrm{NO}_{3}\right)_{2} \cdot 4 \mathrm{H}_{2} \mathrm{O}, 2.5 \mathrm{mM} \mathrm{KNO}_{3}, 0.5 \mathrm{mM} \mathrm{NH}_{4} \mathrm{NO}_{3}, 0.5 \mathrm{mM} \mathrm{KH}_{2} \mathrm{PO}_{4}, 1 \mathrm{mM} \mathrm{MgSO}_{4} \cdot 7 \mathrm{H}_{2} \mathrm{O}, 0.05$ mM Fe-EDTA, $0.005 \mathrm{mM} \mathrm{KI}, 0.1 \mathrm{mM} \mathrm{H}_{3} \mathrm{BO}_{3}, 0.1 \mathrm{mM} \mathrm{MnSO}_{4} \cdot \mathrm{H}_{2} \mathrm{O}, 0.03 \mathrm{mM} \mathrm{ZnSO}_{4} \cdot 7 \mathrm{H}_{2} \mathrm{O}, 0.0001 \mathrm{mM}$ $\mathrm{CuSO}_{4} \cdot 5 \mathrm{H}_{2} \mathrm{O}, 0.001 \mathrm{mM} \mathrm{Na}_{2} \mathrm{MO}_{4} \cdot 2 \mathrm{H}_{2} \mathrm{O}$, and $0.0001 \mathrm{mM} \mathrm{CoCl}_{2} \cdot 6 \mathrm{H}_{2} \mathrm{O}$.

The cotyledons of all samples were excised to eliminate any additional supply of nutrition. When the seedlings reached the two-leaf stage, they were treated with $1 / 2$ Hoagland nutrient solution with two $\mathrm{K}^{+}$concentrations, $\mathrm{K}^{+} 0.5 \mathrm{mmol} \mathrm{L}^{-1}$ (K0.5) and $\mathrm{K}^{+} 3.0 \mathrm{mmol} \mathrm{L}^{-1}$ (K3.0). Two seedlings were used as a unit and three replicates were performed (stored in two copies, one for RNA-Seq and one for real-time quantitative PCR verification). In experiment I, samples were taken at 3, 6, 9, 12, $15 \mathrm{~d}$, after treatment for root architecture analysis ( 30 replicates for each genotype and treatment), and in experiment II, samples were taken at $3 \mathrm{~d}(72 \mathrm{~h})$ after treatment for RNA-Seq (6 replicates for each genotype and treatment).

For exogenous auxin effect on root formation, surface sterilized seeds of Line 7 and Line 20 were germinated in a moistened petri dish in a plant light incubator (Ningbo RXZ-400D-4) for $60 \mathrm{~h}$ at 60\% humidity and $37^{\circ} \mathrm{C}$. Then three germinated seeds were put into the Phyotc culture bag as a unit, and three replicates were performed for each treatment. This experiment designed three exogenous IAA (indol-3-acetic acid, Coolaber) concentrations at $0.1,1$ and $5 \mu \mathrm{M}$ over $\mathrm{K}^{+} 0.5$ and $\mathrm{K}^{+} 3.0$ treatments, and the treatment with only $1 / 2$ Hoagland nutrient solution was as control. In the beginning, $10 \mathrm{~mL} 1 / 2$ Hoagland nutrient solution was added to each bag in light incubator under $12 \mathrm{~h} /$ dark and $12 \mathrm{~h} /$ light cycle for 7 days. After that, $5 \mathrm{~mL}$ nutrient solution was added to the culture bag daily.

\subsection{Measurements}

K contents of plants were determined by flame spectrophotometer [4].

Root morphological parameters, including total root length, surface area, root average diameter were examined with Win-RHIZO 2004 (Regent Instruments, Quebec, Canada), an interactive, scanner-based image-analysis system [6].

$$
\text { K sensitivity }=100 \% \times(\text { dry weight of CK }- \text { dry weight of LK)/dry weight of CK, }
$$

$\mathrm{K}$ internal use efficiency $=$ biomass produced per unit $\mathrm{K}$.

\subsection{Library Construction and Sequencing}

Four root tissue samples, including two genotypes (Line 20 and Line 7) and two treatments (LK and $\mathrm{CK}$ ), were collected at $72 \mathrm{~h}$ after treatment. The experiment consisted of three biological replicates. Total RNA was extracted from the root using TRIzol ${ }^{\circledR}$ Reagent according to the manufacturer's instructions (Invitrogen, Carlsbad, CA, USA) and genomic DNA was removed using DNase I (TaKara, Shiga, Japan). Then RNA quality was determined by 2100 Bioanalyser (Agilent, Santa Clara, CA, USA) and quantified using the ND-2000 (NanoDrop Technologies, Waltham, MA, USA). Only high-quality RNA sample (OD260/280 = 1.8 2.2, OD260/230 $\geq 2.0, \mathrm{RIN} \geq 6.5,28 \mathrm{~S}: 18 \mathrm{~S} \geq 1.0,>10 \mu \mathrm{g}$ ) was used to construct sequencing library. A cDNA library was sequenced using an Illumina HiSeq 4000 platform at 
Shanghai Majorbio Biopharm Technology Co., Ltd. (Shanghai, China). Quality control was performed to eliminate low-quality reads, adaptor polluted reads and ambiguous Ns reads [35].

\subsection{Gene Expression Verification by Quantitative Real-Time PCR (qRT-PCR)}

According to RNA-Seq data, eight differentially expressed genes (DEGs) were randomly selected to verify expressions in sequencing via the RT-qPCR. Total RNA $(0.3 \mu \mathrm{g})$ from each selected gene was treated with gDNA wiper mix and translated into the first strand cDNA, which was stored at $-20^{\circ} \mathrm{C}$ for subsequent analysis. All RT-qPCRs were performed in three technical replicates in the following steps: $95^{\circ} \mathrm{C} 10 \mathrm{~min} ; 95^{\circ} \mathrm{C} 10 \mathrm{~s}, 60^{\circ} \mathrm{C} 15 \mathrm{~s}, 72{ }^{\circ} \mathrm{C} 20 \mathrm{~s}, 40$ cycles. Outliers were manually discarded. The housekeeping gene Actin was used as an internal standard to estimate the relative expression (Table 1). Then the gene expressions were standardized with the $2^{-\Delta \Delta \mathrm{Ct}}$ method [36].

Table 1. Primers used for amplifying candidate and control genes for RT-qPCR.

\begin{tabular}{|c|c|c|}
\hline Gene ID. & Fprimer $5^{\prime}-3^{\prime}$ & Rprimer $5^{\prime}-3^{\prime}$ \\
\hline Glyma04g39380.1(Actin) & TTTGCTGGTGATGATGCTC & ACCTCTTTTTGACTGGGCT \\
\hline Glyma01g40850 & CGTCATTCAAAGGCAATGGTTA & TTTTACACAACTGGGCTTCAAG \\
\hline Glyma10g32080 & САСТTTTСТССAAGAAGAAGCC & GATCCTTCTGTCAGGACCATAC \\
\hline Glyma14g23300 & GTGCAATTGCGACCCTTATATT & ATAAACACAAGCTAGGAGCCTT \\
\hline Glyma15g40140 & CTGATGTCTTCAAGGCATTAGC & CCСAATCAGTGACAATGTGATC \\
\hline Glyma01g06774 & AATGCAGTTACTAGCTACACGA & CTTATCAGAGTAGGTGCGACAT \\
\hline Glyma02g30714 & GTCACTTGCAGAAATATCGGAC & CTGTTGAAGTTCAGTGACCATG \\
\hline Glyma07g02540 & GAAATTCATAGAAGGTGCGGAC & CACCATTGTTCTTGGAGCTTAC \\
\hline Glyma05g00740 & CACGGATGGTTCCAACATTATC & GGGATGCCTACAAAAGAAAGTG \\
\hline
\end{tabular}

\subsection{Statistical Analysis}

Data including plant biomass, $\mathrm{K}$ concentration, root morphological parameters were analysed with SPSS Version 17.0 (SPSS Inc., Chicago, IL, USA). One-Way ANOVA tests were used to assess the differences between treatments at significant levels at $p<0.05$. Pearson correlation was performed at $p<0.05$ and $p<0.01$ levels.

\section{Results}

\subsection{Characteristics of Dry Matter and K Accumulation}

As shown in Figure 1, dry matter accumulation increased dramatically from 3 to 15 days at low $\mathrm{K}$ stress. Dry matter accumulation of K high-efficiency type (Line 20) was significantly higher than that of K low-efficiency type (Line 7) under both low K (LK) and normal K (CK) conditions, though low K treatment significantly decreased the dry matter accumulation in two genotypes with less affected in Line 20 than Line 7. Additionally, K sensitivity of Line 20 was significantly lower than Line 7 (Figure 1).

The K accumulation in two genotypes also showed an increasing trend from 3 to 15 days after treatment (Figure 2). Compared with Line 7, Line 20 had a higher K content under both LK and CK conditions. At $15 \mathrm{~d}$ after treatment, the $\mathrm{K}$ accumulation with low $\mathrm{K}$ treatment reached $1.23 \mathrm{~g} \mathrm{plant}^{-1}$ in Line 20, but only $0.87 \mathrm{~g} \mathrm{plant}^{-1}$ in Line 7 . At the same time, LK stress enhanced the K internal use efficiency (KIUE) of the two genotypes with 11.7\% increase in Line 20 (Figure 2). 


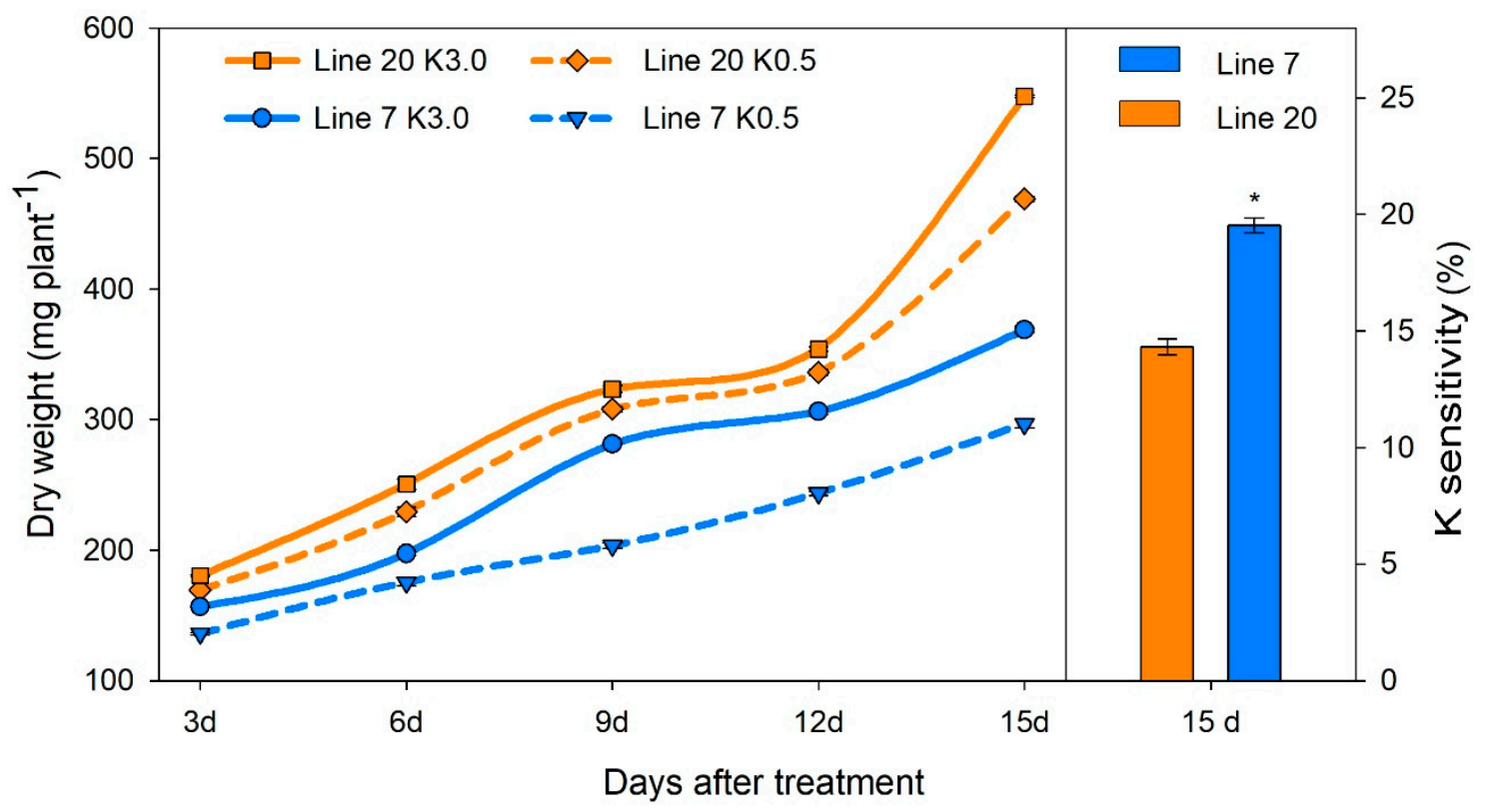

Figure 1. Dry matter accumulation in $\mathrm{K}$ high-efficiency and $\mathrm{K}$ low-efficiency vegetable soybean genotypes under low $\mathrm{K}(\mathrm{LK})$ and normal $\mathrm{K}(\mathrm{CK})$ conditions. * means significant differences at $p=0.05$ level.

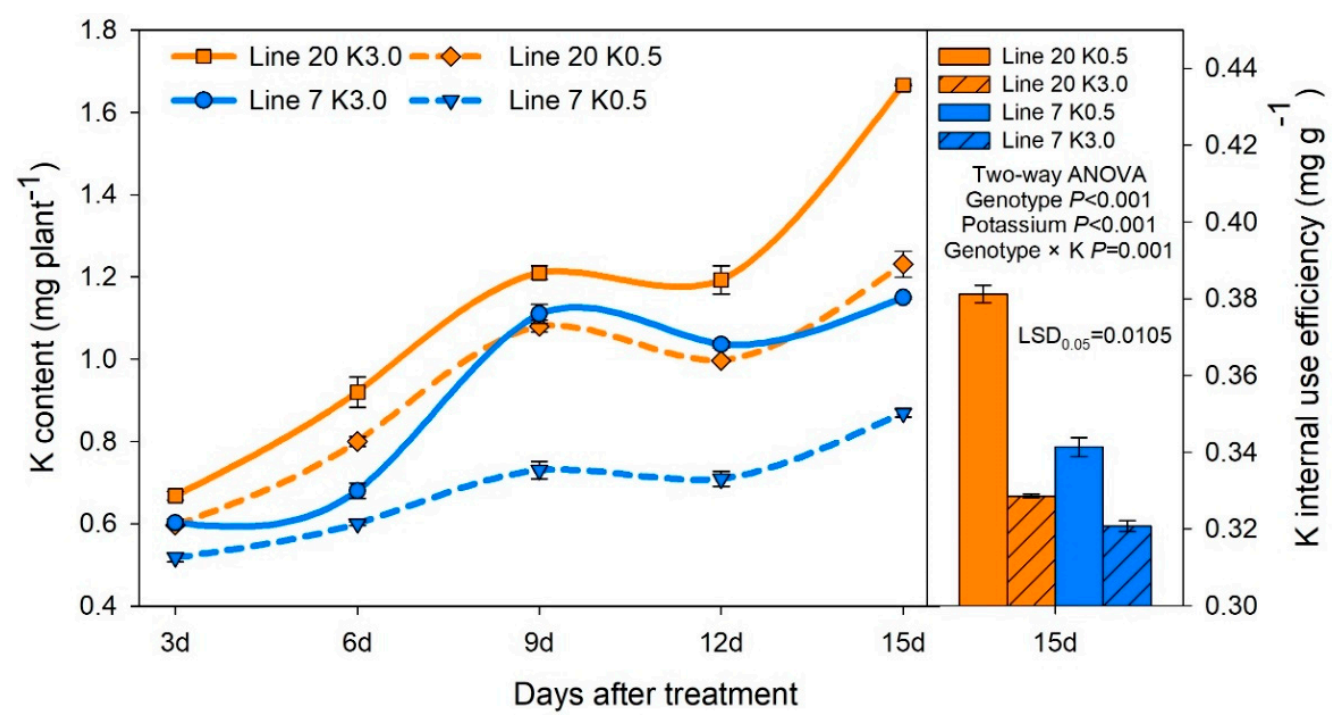

Figure 2. Potassium content in $\mathrm{K}$ high-efficiency and $\mathrm{K}$ low-efficiency vegetable soybean genotypes under low $\mathrm{K}(\mathrm{LK})$ and normal $\mathrm{K}(\mathrm{CK})$ conditions.

\subsection{Root Morphological Characteristics}

The morphological characteristics of the root system are important indicators of plant potassium uptake. In the present study, with seedlings growth, low K stress generally increased the total root length, surface area, and root volume in Line 20, but decreased those parameters in Line 7 (Figure 3). For instance, low $\mathrm{K}$ stress increased the total root length by $25.3 \%$ in Line 20 but decreased the total root length by $53.5 \%$ in Line 7 at $15 \mathrm{~d}$ after treatment. From 3 to $15 \mathrm{~d}$ after treatment under low $\mathrm{K}$ (LK) and normal K (CK) concentrations, the total root length increased by $3.6(492 \mathrm{~cm})$ and 4.0 times $(401 \mathrm{~cm})$ in Line 20, and by $2.9(191 \mathrm{~cm})$ and $5.2(510 \mathrm{~cm})$ times in Line 7 respectively. More lateral roots (LRs) were found in Line 20 compared with Line 7 under both K concentrations. Under the LK and CK treatment, LR of Line 20 was $30.6 \%$ and $28.3 \%$ higher than that of Line 7 , respectively. 

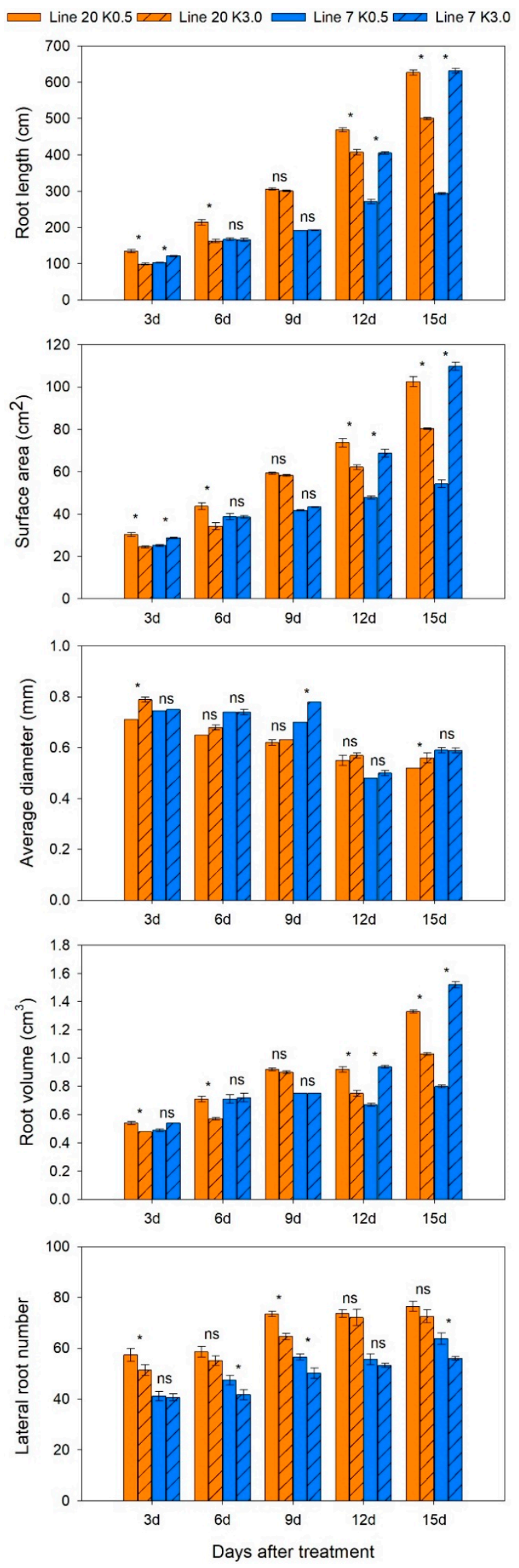

Figure 3. Root morphological characteristics in $\mathrm{K}$ high-efficiency and $\mathrm{K}$ low-efficiency vegetable soybean genotypes under low $\mathrm{K}(\mathrm{LK})$ and normal $\mathrm{K}(\mathrm{CK})$ conditions. * means significant differences at $p=0.05$ level; ns means not significant. 
Additionally, the lateral root number was significantly correlated with total root length, root surface area, root volume, $\mathrm{K}$ internal use efficiency, dry matter weight and $\mathrm{K}$ content (Table 2).

Table 2. Correlation analysis of root morphological parameters with KIUE, dry weight, and K accumulation.

\begin{tabular}{llllllll}
\hline & LRN & TRL & SA & AD & RV & KIUE & DW \\
\hline TRL & $0.694^{* *}$ & & & & & & \\
SA & $0.464^{* *}$ & $0.989^{* *}$ & & & & & \\
AD & $-0.678^{* *}$ & $-0.787^{* *}$ & $-0.734^{* *}$ & & & & \\
RV & $0.534^{* *}$ & $0.927^{* *}$ & $0.972^{* *}$ & $-0.603^{* *}$ & & & \\
KIUE & $0.604^{* *}$ & $0.744^{* *}$ & $0.711^{* *}$ & $-0.776^{* *}$ & $0.624^{* *}$ & & \\
DW & $0.783^{* *}$ & $0.878^{* *}$ & $0.854^{* *}$ & $-0.694^{* *}$ & $0.773^{* *}$ & $0.634^{* *}$ & \\
KC & $0.720^{* *}$ & $0.767^{* *}$ & $0.753^{* *}$ & $-0.562^{* *}$ & $0.688^{* *}$ & 0.378 & $0.951^{* *}$ \\
\hline
\end{tabular}

** means significant differences at $p=0.01$ level; LRN, lateral root number; TRL, total root length; SA, surface area; $\mathrm{AD}$, average diameter; RV, root volume; KIUE, K internal use efficiency; DW, dry weight; KC, K content.

\subsection{Effect of Exogenous IAA on Lateral Root Formation}

To verify the effect of auxin signal transduction to root formation, we designed an exogenous auxin application experiment. The primary root length of HKE and LKE genotypes demonstrated different patterns in response to exogenous IAA application (Figure 4a). The exogenous IAA application at low $\mathrm{K}$ stress inhibited primary root elongation in LKE genotype, but not in HKE genotype. As shown in Figure $4 b$, low concentration of exogenous IAA $(0.1 \mu \mathrm{M})$ application induced more lateral root formation in both HKE and LKE genotypes under two K conditions. Under the LK condition with $0.1 \mu \mathrm{M}$ exogenous IAA, 145 lateral roots were found in Line 20, which was significantly higher than that of Line $7(p<0.05)$. With the increase in exogenous IAA concentration, lateral root number decreased dramatically. In HKE genotype, low $\mathrm{K}$ stress generally increased lateral root number up to $1 \mu \mathrm{M}$ exogenous IAA. While in LKE genotype, more lateral roots were found in the normal $\mathrm{K}$ condition when exogenous IAA concentration was higher than $1 \mu \mathrm{M}$.

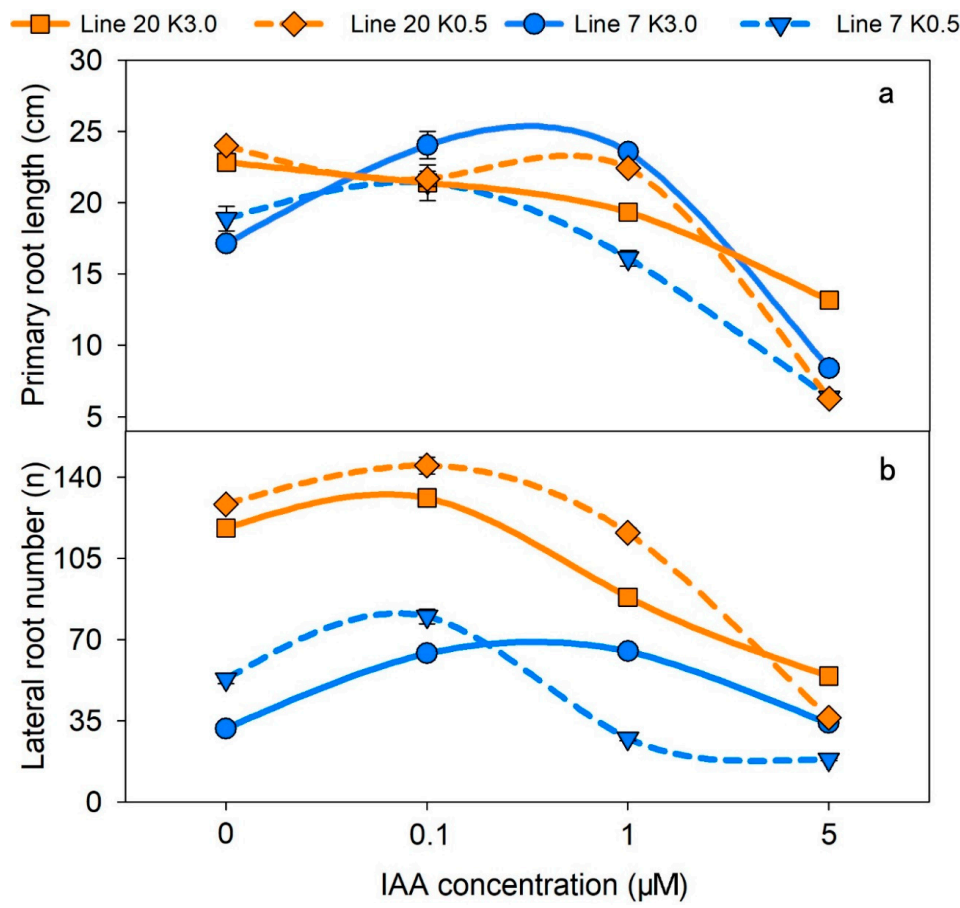

Figure 4. Effect of exogenous IAA on primary root length (a) and lateral root number (b) under the LK and CK conditions. 


\subsection{Transcriptome Responses to K Starvation}

\subsubsection{Overview of the RNA Sequencing Data}

To investigate alterations in the root gene expression regulated by $\mathrm{K}^{+}$starvation, RNA-Seq analysis was conducted on Line 20 and Line 7 roots using Illumina sequencing technology. After quality control and cleaning, samples provided $>4.5$ million clean reads. The genome map rates of the twelve libraries ranged $86.94-95.6 \%$, the unique matching ratio ranged $78.8 \%$ to $93.3 \%$, the reads from twelve libraries were combined and assembled into 54,174 non-redundant unigenes.

\subsubsection{Analysis of Differentially Expressed Genes (DEGs)}

By comparing transcriptome libraries between $\mathrm{K}$ high-efficiency genotype Line 20 and $\mathrm{K}$ low-efficiency genotype Line 7, under low K stress and normal K concentration conditions, differentially expressed genes (DEGs) were identified using the combined criteria of $p$-adjust $<0.05$ and $\mid \log _{2} \mathrm{FCl} \geq 1$. Using these standards, 1432 (774 up-regulated and 658 down-regulated) and 1900 (1137 up-regulated and 763 down-regulated) genes were differentially expressed in low K (LK) and normal K (CK) conditions, respectively (Figure 5). Among them, 405 genes were co-up-regulated and 417 were co-down-regulated in both conditions. A total of 364 and 235 genes were specific up- and down-regulated under the LK condition and 726 and 341 genes were specific up- and down-regulated under the CK condition. Meanwhile, 11 inverse regulated genes were identified between LK and CK conditions. These results were then further analyzed.

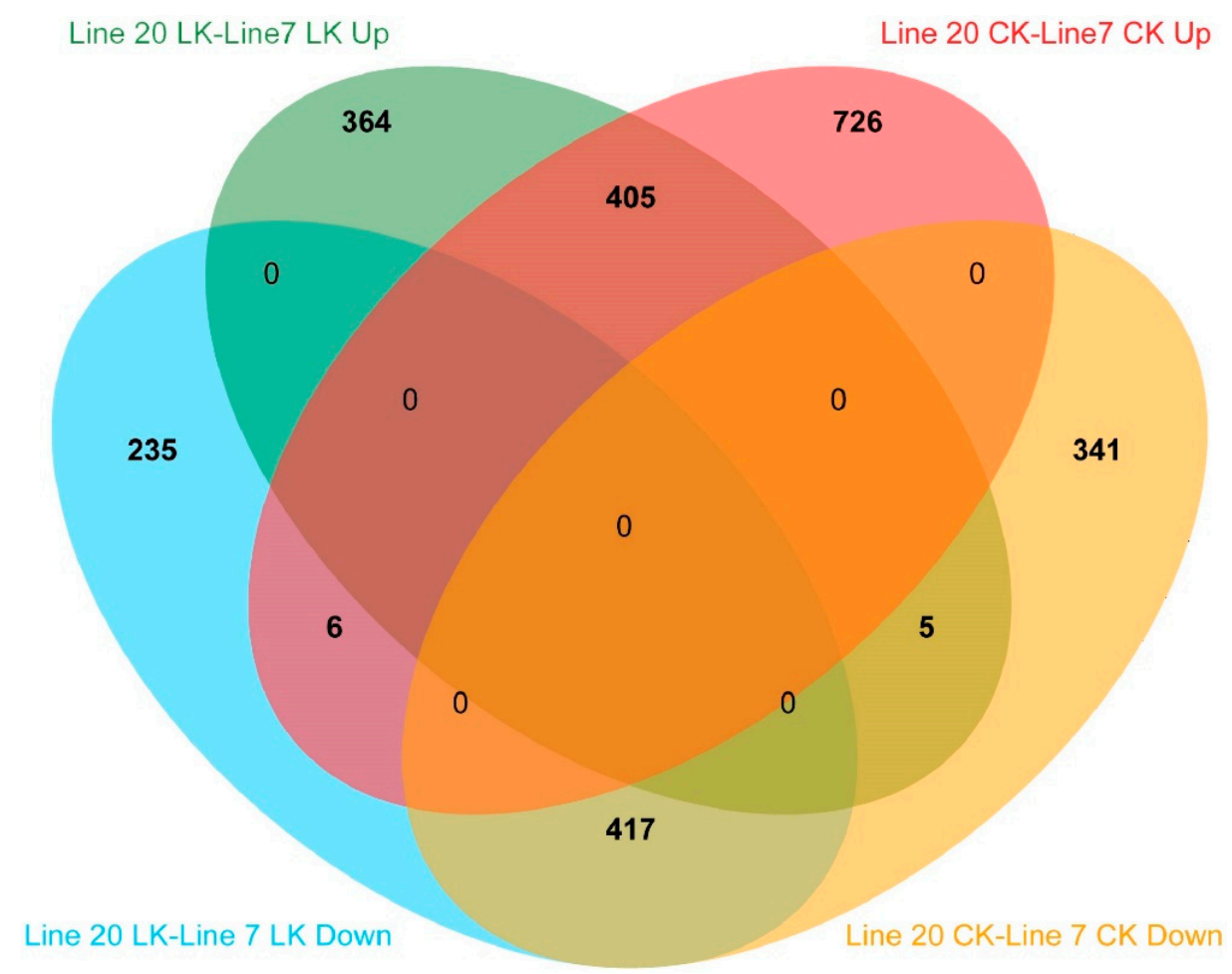

Figure 5. A Venn diagram describing overlaps among differentially expressed genes (DEGs) DEGs were screened with the $p$-adjust $<0.05$ and $|\log 2 \mathrm{FC}| \geq 1$.

\subsubsection{Enrichment Analysis of DEGs}

Gene Ontology (GO) annotations analysis revealed that under low- and normal $\mathrm{K}^{+}$conditions, DEGs were both categorized into 46 (GO) terms (Figure S1). To reveal the significantly different biological functions and processes between the two K efficiency types, GO and the Kyoto Encyclopedia of Genes and Genomes (KEGG) enrichment analysis were implemented. Compared with the KLE genotype (Line 7) under the LK condition, 364 individually up-regulated genes were significantly 
( $p$-corrected $\leq 0.05$ ) enriched in $72 \mathrm{GO}$ terms, which were mostly related to "transport" or "transporter activity" processes. The processes involved include "ion/anion transport (GO: 0006811/0006820)", "carboxylic acid transport (GO: 0046942)", "transmembrane transport (GO: 0055085)", "nitrogen compound transport (GO: 0071705)" and "amino acid transport (GO: 0006865)", "transmembrane transporter activity (GO: 0022857)", "substrate-specific transporter activity (GO: 0022891)", "organic acid transmembrane transporter activity (GO: 0005342)", and "transporter activity (GO: 0005215)" terms (Table S1, Figure 5). Meanwhile, these up-regulated genes were significantly enriched in "nitrogen metabolism (map00910)" and "fructose and mannose metabolism (map00051)" KEGG pathways. In contrast, no significantly enriched GO terms or KEGG pathways were found in individually down-regulated genes. While, under normal $\mathrm{K}$ condition, 726 individually up-regulated genes were significantly enriched in $114 \mathrm{GO}$ terms (Table S2), such as "single-organism catabolic/metabolic process (GO: 0044712/0044710)", "secondary metabolic process (GO: 0019748)", "reactive oxygen species metabolic process (GO: 0072593)", and "S-glycoside metabolic process (GO: 0016143)" processes. These DEGs were significantly enriched in 7 KEGG pathways (phenylpropanoid biosynthesis, cyanoamino acid metabolism, glutathione metabolism, plant-pathogen interaction, carotenoid biosynthesis, starch and sucrose metabolism, plant hormone signal transduction). However, for down-regulated DEGs under normal $\mathrm{K}^{+}$condition, 341 individually down-regulated genes were significantly enriched in 22 GO terms and 3 KEGG pathways (Table S3). As for co-up-regulated DEGs, 405 genes were significantly enriched in 44 GO terms (Table S4), which were related to "response to stimulus (GO: 0050896)", "signal transduction (GO: 0007165)", "protein phosphorylation (GO: 0006468)", "plasma membrane (GO: 0005886)", "ion binding (GO: 0043167)", and "kinase activity (GO: 0016301)". These co-up-regulated genes were only significantly enriched in the "plant-pathogen interaction (map04626)" KEGG pathway. Whereas, co-down-regulated DEGs were enriched in 19 GO terms (Table S5), including "response to stimulus (GO: 0050896)", "response to stress (GO: 0006950)", “defense response (GO: 0006952)", and "signal transduction (GO: 0007165)" as well. No significant enrichment of KEGG pathway was found in the DEGs with down regulation.

\subsubsection{Potassium Absorption- and Translocation-Related Genes}

Table 3 lists the DEGs related to $\mathrm{K}^{+}$uptake and translocation in this study by using the combined criteria of $p$-adjust $<0.05$ and FC $\geq 1$. The gene Glyma01g30485 encoding homologous gene of Potassium transporter 1 (Arabidopsis thaliana, KUP1), was the greatest differentially expressed potassium transporter gene, which was down-regulated under both sufficient and insufficient $\mathrm{K}^{+}$ conditions. In contrast, compared with Line 7, HAK5 homologous gene Glyma19g45260 in Line 20 was highly expressed under two $\mathrm{K}^{+}$conditions. Moreover, two KUP6 genes (Glyma01g03850 and Glyma18g18810) and one POTASSIUM TRANSPORTER 25-LIKE gene (Glyma08g06060) were differentially expressed at the FC $\geq 1$ level. As for K channels, differentially expressed homologous genes of AKT1 (Glyma17g12740), TPK1 (Glyma14g01790), and TPK3 (Glyma14g03260) were identified. Additionally, some cyclic nucleotide-gated ion channels (CNGC15A, CNGC20, CNGC14, and CNGC2) were also differentially expressed.

\subsubsection{DEGs Significantly Enriched in Transport-Related Genes}

Under low K condition, higher expressed genes in Line 20 were significantly enriched in 28 transport-related GO terms, as mentioned above. In total, 56 genes were included in those GO terms (Table S6) like genes encoding 'Calcium-transporting ATPase (Glyma08g23760)', 'WAT1-related protein (Glyma06g11790, Glyma03g33020, Glyma19g35720, Glyma06g11780, Glyma04g42970)', 'cation/ $\mathrm{H}^{+}$ exchanger 20 (Glyma13g39850)', 'Water channel activity (Glyma11g35030)', 'high affinity nitrate transporter (Glyma13g39850)', 'Ammonium transporter (Glyma10g31080)', and 'Soybean phosphate transporter protein 4 (Glyma10g00950)'. 
Table 3. List of $\mathrm{K}^{+}$stress-responsive genes related to $\mathrm{K}^{+}$acquisition and transport.

\begin{tabular}{|c|c|c|c|}
\hline Gene ID & $\begin{array}{c}\text { LK } \\
\left(\log _{2} \text { Line 20/Line 7) }\right.\end{array}$ & $\begin{array}{c}\text { CK } \\
\left(\log _{2} \text { Line 20/Line 7) }\right.\end{array}$ & Annotation \\
\hline Glyma01g30485 & -4.02 & -3.67 & $\begin{array}{l}\text { Potassium transporter 1, KUP1 } \\
\text { (Arabidopsis thaliana) }\end{array}$ \\
\hline Glyma19g45260 & 0.97 & 0.39 & $\begin{array}{l}\text { High affinity } \mathrm{K}^{+} \text {transporter } 5 \text {, } \\
\text { HAK5 (Arabidopsis thaliana) }\end{array}$ \\
\hline Glyma01g03850 & -0.61 & - & $\begin{array}{l}\mathrm{K}^{+} \text {uptake permease } 6, \mathrm{KUP6} \\
\text { (Arabidopsis thaliana) }\end{array}$ \\
\hline Glyma18g18810 & -0.53 & - & $\begin{array}{l}\mathrm{K}^{+} \text {uptake permease } 6, \mathrm{KUP} 6 \\
\text { (Arabidopsis thaliana) }\end{array}$ \\
\hline Glyma08g06060 & 0.60 & - & $\begin{array}{l}\text { Potassium transporter } 25 \text {-like } \\
\text { (Glycine max) }\end{array}$ \\
\hline Glyma17g12740 & 0.77 & 0.78 & $\begin{array}{l}\text { Potassium channel AKT1 } \\
\text { (Arabidopsis thaliana, AKT1) }\end{array}$ \\
\hline Glyma09g11770 & 0.97 & - & $\begin{array}{l}\text { CBL-interacting protein kinase } 23 \text {, } \\
\text { CIPK23 (Arabidopsis thaliana) }\end{array}$ \\
\hline Glyma05g05580 & - & 0.51 & $\begin{array}{l}\text { Calcineurin B-like protein 9, CBL9 } \\
\text { (Arabidopsis thaliana) }\end{array}$ \\
\hline Glyma14g01790 & - & 0.67 & $\begin{array}{l}\text { Two-pore potassium channel 1, } \\
\text { TPK1 (Arabidopsis thaliana) }\end{array}$ \\
\hline Glyma14g03260 & -1.06 & -1.85 & $\begin{array}{l}\text { Two-pore potassium channel 3, } \\
\text { TPK3 (Arabidopsis thaliana) }\end{array}$ \\
\hline Glyma18g49890 & - & 0.89 & $\begin{array}{l}\text { Cyclic nucleotide-gated ion channel } \\
2, \text { CNGC2 (Arabidopsis thaliana) }\end{array}$ \\
\hline Glyma04g08085 & 0.54 & - & $\begin{array}{l}\text { Probable cyclic nucleotide-gated ion } \\
\text { channel 14, CNGC14 } \\
\text { (Arabidopsis thaliana) }\end{array}$ \\
\hline Glyma13g20420 & 1.23 & - & $\begin{array}{l}\text { Cyclic nucleotide-gated channel 15, } \\
\text { CNGC15 (Arabidopsis thaliana) }\end{array}$ \\
\hline Glyma16g34381 & 0.65 & - & $\begin{array}{l}\text { Probable cyclic nucleotide-gated ion } \\
\text { channel 20, chloroplastic, CNGC20 } \\
\text { (Arabidopsis thaliana) }\end{array}$ \\
\hline
\end{tabular}

"-" represents no significant difference.

\subsubsection{Identification of K Starvation Responsive Transcription Factors (TFs)}

Considering the importance of TFs in regulating stress-responsive genes, this study analyzed differentially expressed TFs between two potassium efficiency vegetable soybean genotypes. The result revealed that $82 \mathrm{TFs}$ belonging to 22 transcription factor families were differentially expressed under low $\mathrm{K}^{+}$condition in both genotypes (Figure S2), such as bHLH (13), NAC (9), bZIP (9), AP2/ERF (6), WRKY (6), MYB-related (6) and MYB (6) families. Meanwhile, 121 TFs belonging to 22 transcription factor families were differentially expressed in normal $\mathrm{K}^{+}$condition (Figure S2).

\subsubsection{Differences in Plant Hormone-Related Gene Expression}

Auxin

Thirty-two genes were differentially expressed between K high-efficiency and low-efficiency genotypes over two $\mathrm{K}^{+}$concentrations (Table S7). The results identified four auxin response factor (ARF4, 7 and 19), two dioxygenase for auxin oxidation (DAO), three auxin-binding protein (ABP19a), three probable indole-3-acetic acid-amido synthetase (GH3.1 and 3.5), seven auxin-induced protein and eleven auxin-responsive protein (SAUR32, 40 and 71 and IAA11, 13, 14 and 29-like) genes. Additionally, an auxin efflux carrier component 3 (PIN3) and an auxin transporter-like protein 1 (AUX1/LAX1) gene were also differentially expressed. 
Ethylene

Twenty-eight DEGs were identified related to ethylene (Table S8). Among them, twenty-two DEGs were identified encoding ethylene-responsive transcription factors, nineteen of which were only significantly up-regulated under normal $\mathrm{K}^{+}$concentration. The other three genes were differentially expressed under low $\mathrm{K}^{+}$condition, two of them were significantly down-regulated (Glyma18g48741 and Glyma04g43040).

Jasmonic Acid

Under normal $\mathrm{K}^{+}$condition, seven DEGs were identified related to jasmonic acid, two of them were also differentially expressed under low $\mathrm{K}^{+}$condition (Table S9). Among them, three genes involved in alpha-linolenic acid metabolism process (Glyma04g03740, Glyma17g05770, and Glyma13g16950) were identified. Additionally, JAR1 and GRI and two JAZ genes were also differentially expressed.

Cytokinin

Under low K stress, seven DEGs involved in "cytokinin biosynthetic process", "response to cytokinin" and/or "cytokinin metabolic process" processes were down-regulated in Line 20, whereas two DEGs involved in "cytokinin metabolic process" were up-regulated in Line 7. Additionally, five cytokinin-related DEGs were found in Line 20 compared with Line 7 under low K or normal K condition (Table S10).

\section{Abscisic Acid}

In total, seventeen abscisic acid-related DEGs were found under different $\mathrm{K}$ cultural conditions for the two genotypes. The differentially expressed genes were generally involved in the "abscisic acid-activated signaling pathway" and "response to abscisic acid" and "abscisic acid biosynthetic process" processes (Table S11).

\section{Gibberellin}

There were 10 differentially expressed genes related to gibberellin (Table S12), which were mainly involved in the "gibberellin catabolic process", "response to gibberellin", and "gibberellin biosynthetic process". Six of these differentially expressed genes were highly expressed in Line 20 under normal K condition. However, four out of the five DEGs under low K condition were only down-regulated in Line 20, the other one DEGs, RGL1-like (Glyma15g15110) was both up-regulated under both K conditions.

Genes related to root development were also found to have significant differential expression in varieties with different potassium efficiency and at different potassium levels (Table 4). Two LBD family genes that may be involved in auxin signaling regulating lateral root generation were differentially expressed. Four Expansin-like genes related to lateral root generation were found to be up-regulated by CK treatment, among which Glyma01g35070 and Glyma01g41330 were also up-regulated by LK treatment. Four SCARECROW transcription factor genes of GRAS family were identified, and one MADS-box transcription factor family gene ANR1 involved in lateral root development regulation [37] was differentially expressed. Additionally, one DGK2 gene and one XTH24 gene were also differentially expressed.

\subsubsection{Reliability Verification of RNA-Seq Sequencing Results}

To verify the reliability of RNA-Seq sequencing results, eight differentially expressed genes were randomly selected for real-time quantitative PCR validation (Figure 6). The results showed that the coefficients $\left(\mathrm{r}^{2}\right)$ of the two methods were 0.84 , so the transcriptome expression profile data could be used for further analysis. 
Table 4. Differentially expressed genes related to root development.

\begin{tabular}{|c|c|c|c|}
\hline \multirow{2}{*}{ Gene ID } & LK & CK & \multirow{2}{*}{ Annotation } \\
\hline & $\left(\log _{2} \mathrm{FC}\right)$ & $\left(\log _{2} \mathrm{FC}\right)$ & \\
\hline GLYMA05G08870 & 1.25 & 1.16 & $\begin{array}{l}\text { LOB domain-containing protein 25, LBD25 } \\
\text { (Arabidopsis thaliana) }\end{array}$ \\
\hline GLYMA03G02620 & -1.45 & - & $\begin{array}{l}\text { LOB domain-containing protein } 18, \text { LBD18 } \\
\text { (Arabidopsis thaliana) }\end{array}$ \\
\hline GLYMA05G02530 & - & - & $\begin{array}{l}\text { Protein LATERAL ORGAN BOUNDARIES, } \\
\text { LOB (Arabidopsis thaliana) }\end{array}$ \\
\hline GLYMA01G35070 & 3.70 & 3.36 & $\begin{array}{l}\text { Expansin-like B1 (Oryza sativa subsp. } \\
\text { Japonica) }\end{array}$ \\
\hline GLYMA01G41330 & 1.18 & 1.63 & Expansin-like B1(Glycine max) \\
\hline GLYMA11G04080 & - & 1.00 & Expansin-like B1 (Arabidopsis thaliana) \\
\hline GLYMA09G37090 & - & 1.04 & $\begin{array}{l}\text { Expansin-like A1, EXPA1 } \\
\text { (Arabidopsis thaliana) }\end{array}$ \\
\hline GLYMA02G38091 & 0.83 & - & $\begin{array}{l}\text { MADS-box transcription factor ANR1, } \\
\text { ANR1 (Arabidopsis thaliana) }\end{array}$ \\
\hline GLYMA20G26940 & - & 1.10 & $\begin{array}{l}\text { Zinc finger protein ZAT6, ZAT6 } \\
\text { (Arabidopsis thaliana) }\end{array}$ \\
\hline GLYMA12G02530 & -2.42 & -2.70 & $\begin{array}{l}\text { Scarecrow-like protein 23, SCL23 } \\
\text { (Arabidopsis thaliana) }\end{array}$ \\
\hline GLYMA10G04421 & 1.29 & 2.36 & $\begin{array}{l}\text { Protein SCARECROW, SCR } \\
\text { (Arabidopsis thaliana) }\end{array}$ \\
\hline GLYMA07G18934 & 1.58 & 1.57 & $\begin{array}{l}\text { SCARECROW-LIKE protein 7, SCL7 } \\
\text { (Populus euphratica) }\end{array}$ \\
\hline GLYMA17G17710 & 0.84 & 1.21 & $\begin{array}{l}\text { Scarecrow-like protein 32, SCL32 } \\
\text { (Arabidopsis thaliana) }\end{array}$ \\
\hline GLYMA03G02563 & -1.63 & -2.09 & $\begin{array}{l}\text { Kinesin-like protein KIN-UB, KINUB } \\
\text { (Arabidopsis thaliana) }\end{array}$ \\
\hline GLYMA05G32970 & -1.08 & -0.50 & $\begin{array}{l}\text { Diacylglycerol kinase 2, DGK2 (Arabidopsis } \\
\text { thaliana) }\end{array}$ \\
\hline GLYMA13G01110 & - & 1.06 & $\begin{array}{l}\text { Xyloglucan } \\
\text { endotransglucosylase/hydrolase protein 24, } \\
\text { XTH24 (Arabidopsis thaliana) }\end{array}$ \\
\hline
\end{tabular}

"-" represents no significant difference.

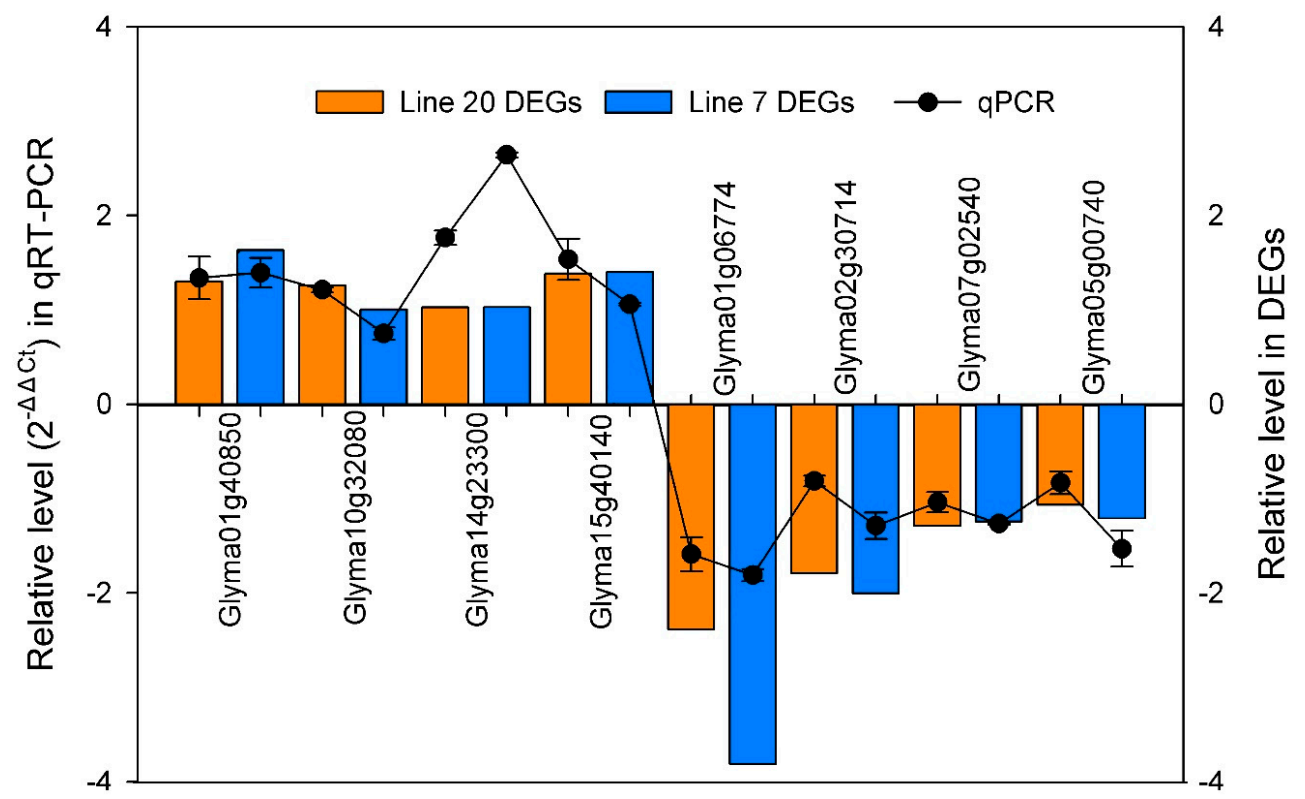

Figure 6. Comparison of results between RNA-Seq and qPCR. 


\section{Discussion}

\subsection{Root Morphology and High Potassium Efficiency in Vegetable Soybean}

The high potassium efficiency (HKE) genotypes should have a strong capacity to uptake $\mathrm{K}^{+}$ associated with the ability to convert per unit potassium into more dry matter or yield [33], which has been found in previous studies [5,6], and also confirmed in this study. The HKE genotype Line 20 is a representative genotype that has a stronger $\mathrm{K}^{+}$uptake and use capacity than the low K-efficiency (LKE) genotype Line 7 due to significant differences in specific root morphological and physiological characteristics [6]. A key strategy of plants to adapt to changing moisture and nutrient availability in soil is the formation of a postembryonic root system [38,39]. Nutrient deficiency including potassium starvation has a significant influence on the root architecture formation of crops [5]. Meanwhile, genotypes with different $\mathrm{K}$ efficiency also have distinct root development strategies to maximize potassium use $[5,40]$. In the present study, the response of root morphology to low K stress was more preferable in HKE genotype Line 20. This was reflected in a stronger expansion and extension capacity of Line 20 under low K stress, such as the increase in total root length, surface area, and root volume. In contrast, $\mathrm{K}$ deficiency significantly inhibited the root development of low K-efficiency type Line 7. The characteristics of root response to low potassium ensure that the HKE genotype has a higher probability of obtaining $\mathrm{K}^{+}$[5]. Additionally, the $30.6 \%$ increase and $28.3 \%$ increase in lateral roots of Line 20 over Line 7 under low potassium (LK) and normal potassium (CK) conditions directly imply that the nutrient uptake efficiency could be improved [41], and characteristics of the HKE root system is closely associated with the uptake and use efficiency of $\mathrm{K}$ [5]. This was demonstrated by the positive correlation of lateral root number and total root length with $\mathrm{K}$ internal use efficiency and $\mathrm{K}$ content in the present study $(p \leq 0.01)$.

Auxin signaling plays an important role in lateral root formation [42]. Auxin flux carriers facilitate auxin transport from the lateral root cap into the oscillation zone, which ensures lateral root formation [22]. According to the results of exogenous IAA application experiment, low-concentration exogenous IAA helps increase vegetable soybean lateral roots, especially when plants suffering low $\mathrm{K}$ stress. Interestingly, in low $\mathrm{K}$ condition, lateral roots of HKE genotype has a wider response threshold to IAA concentration (up to $1 \mu \mathrm{M}$ ). Therefore, in this aspect, the lateral roots of HKE respond more effectively to auxin signals under low $\mathrm{K}$ conditions, which may play a positive role in the efficient $\mathrm{K}$ uptake by root system [43].

\subsection{Transcriptome Profiling between Two K-Efficiency Vegetable Soybean Genotypes}

Transcriptome profiling provides a feasible method for unveiling the gene regulation mechanism and for elucidating the response mechanism to K deficiency [7,26]. The present study identified 1432 and 1900 of differentially expressed genes (DEGs) under low K and normal K conditions for the two K-efficiency genotypes, which were both categorized into 46 s-level GO terms. It is worth mentioning that under the LK condition, the individually up-regulated genes were significantly ( $p$-corrected $\leq 0.05$ ) enriched in "transport" or "transporter activity" related GO terms. Remarkably, Fan et al. (2014) [7] also found a similar result in more tolerant $\mathrm{K}^{+}$deficiency watermelon $Y S$. This indicated that expression of root transport-related genes is stimulated in HKE vegetable soybean root under low potassium stress. As for co-regulated DEGs, the down-regulated genes were found significantly enriched in genes related to "response to stimulus", "response to stress", "defense response", and "signal transduction". Some studies believed that the repressed genes related to stress and/or defense response can save energy for better root growth in low $\mathrm{K}$ tolerant genotype, which can facilitate $\mathrm{K}^{+}$uptake and increase $\mathrm{K}$ efficiency and tolerance to $\mathrm{K}^{+}$deficiency [7]. As these DEGs were down-regulated under the LK and $\mathrm{CK}$ conditions, the difference might not be caused by low potassium stress but an inherent advantage.

Changes in gene transcription are associated with changes in the expression of transcription factors (TFs). Transcriptional control of the expression of stress-response genes is a crucial part of the plant response to a range of abiotic and biotic stresses [44]. Transcription factors can show some complexity 
and overlap in their responses to different stressors and are likely to lead to new ways of enhancing crop tolerance to environmental stress [23], including low K stress [26]. In this study, a total of 82 DEGs belonging to 22 transcription factor families were identified for the two K-efficiency types under low $\mathrm{K}$ stress, and the major transcription factor families were bHLH (13), NAC (9), bZIP (9), AP2/ERF (6), WRKY (6), MYB-related (6) and MYB (6) (Table S9). These TF families were reported to play a vital role in the transcriptional regulation of plants [45]. For instance, AKSs, the basic helix-loop-helix (bHLH) transcription factors in guard cells of Arabidopsis, facilitated stomatal opening through the transcription of genes encoding inwardly rectifying $\mathrm{K}^{+}$channels in their unphosphorylated state. In soybean, two bHLH transcription factors, GmbHLH57 and GmbHLH300, were identified in response to Fe-deficiency, both of which were expressed in roots and nodules [46]. Our results also identified a GmbHLH300 homologous gene (Glyma03g28630) higher expressed ( $\left.2.80 \log _{2} \mathrm{FC}\right)$ in the HKE genotype. We assume that GmbHLH300 might also be involved in K high-efficiency uptake in vegetable soybean. Many NACtype genes have been found to play roles in shoot apical meristem formation, organ separation and stress tolerance [47-49]. Meng et al. (2007) cloned and initially characterized six NAC-like genes in soybean for the first time, but did not verify its function [50]. Hao et al. (2011) indicated that overexpression of soybean GmNAC20 enhances salt and freezing tolerance and also promotes lateral root formation in transgenic Arabidopsis plants [49]. In this study, we identified nine differentially expressed NACs which may modify and regulate genes that affect potassium efficiency. Wang et al. (2012) also identified some AP2/ERF, WRKY and MYB family transcription factors differentially expressed in low K-resistance in soybeans [26]. The differentially expressed TFs identified in our results are useful in discovering candidate genes related to $\mathrm{K}$ stress tolerance.

\subsection{DEGs Related to K Absorption}

In plant roots, $\mathrm{K}^{+}$absorption from soils is mainly mediated by $\mathrm{K}^{+}$channels and transporters. Potassium is absorbed from the soil into root cells across the membrane, and then to the whole plant through unloading to the xylem [51,52]. The movement of $\mathrm{K}^{+}$involves several steps, including uptake, translocation, and recycling [51]. The candidate genes identified in this study, such as putative potassium transporters, potassium channels, and potassium channel regulatory factors, may play important roles in these processes. The $\mathrm{K}^{+}$uptake permeases (KUPs) encoding plasma membrane $\mathrm{K}^{+} / \mathrm{H}^{+}$symporters have been reported [53]. In this study, a KUP1 (Glyma01g30485) gene was repressed in Line 20 under both LK and CK conditions. Additionally, two KUP6 homologous genes (Glyma01g03850 and Glyma18g18810) were repressed. In Arabidopsis, KUP6 was functionally involved in the $\mathrm{K}^{+}$efflux and KUP6 deletion mutant significantly enhanced lateral root formation in response to exogenous auxin [54].

It has been shown in Arabidopsis thaliana that when the external $\mathrm{K}^{+}$concentration is very low, $\mathrm{K}^{+}$ nutrition depends exclusively on the high-affinity $\mathrm{K}^{+}$transporter 5 (HAK5) [14]; and CIPK23 regulates HAK5-mediated high-affinity $\mathrm{K}^{+}$uptake in roots [55]. In the present study, the homologous genes of HAK5 and CIPK23 were both highly expressed in KHE genotype Line 20 under the LK condition. Thus, we propose that the CIPK23-HAK5 pathway is involved in root $\mathrm{K}^{+}$absorption for HKE vegetable soybean. Additionally, a functionally unknown protein "potassium transporter 25-like (Glycine max)" gene Glyma08g06060 from KUP/HAK/KT family was found higher expressed in Line 20, which may also be involved in $\mathrm{K}^{+}$uptake process. Under normal conditions, low-affinity potassium ion channels are the major way for $\mathrm{K}^{+}$to enter roots. In addition, AKT1 (ARABIDOPSIS $\mathrm{K}^{+}$TRANSPORTER1) has been identified as an inward-rectifying $\mathrm{K}^{+}$channel in Arabidopsis thaliana and plays crucial roles in $\mathrm{K}^{+}$uptake from the soil into root cells $[51,56,57]$. Loss of function of At-AKT1 leads to a reduction of $\mathrm{K}^{+}$uptake and makes plants hypersensitive to low $\mathrm{K}^{+}$stress $[25,56]$. In this study, Glyma17g12740, a homologous gene of the AKT1 gene, was highly expressed in Line 20 but was not affected by low $\mathrm{K}^{+}$ stress. This might be an important internal mechanism of high potassium uptake for HKE genotype.

We also found the homologous genes of CBL9 (Glyma05g05580) and CIPK23 (Glyma09g11770) up-regulated in Line 20 under the CK condition. AKT1 activity was positively regulated by 
CBL1/9-CIPK23 protein complexes in Arabidopsis [25]. The calcineurin B-like protein CBL1 and/or CBL9 interacts with protein kinase CIPK23 at the plasma membrane (PM), where CIPK23 phosphorylates AKT1 and activated AKT1-mediated $\mathrm{K}^{+}$uptake [25]. In this regard, the improvement of the CBL1/9-CIPK23 pathway might also play a role for high K-efficiency vegetable soybean genotype $\mathrm{K}^{+}$uptake.

As a potassium channel gene expressed in the vacuole membrane, TPK1 plays an important role in maintaining osmotic pressure and potassium storage in root [52]. They reported that expression of AtTPK1 could induce $\mathrm{K}^{+}$influx, but AtTPK3 did not form functional $\mathrm{K}^{+}$channels when expressed in E. coli. In Line 20, a TPK1 homologous gene (Glyma14g01790) was found higher expressed under the CK condition, whereas a TPK3 gene (Glyma14g03260) was found lower expressed under both LK and CK conditions. Four cyclic-nucleotide-gated ion channels (CNGC) genes including CNGC2, CNGC12, CNGC15, and CNGC20 were identified differentially expressed in the present study. Since CNGCs are nonselective cation channels that can also transport $\mathrm{K}^{+}$, and are gated by the direct binding of cyclic nucleotides [58], they might also contribute to $\mathrm{K}^{+}$absorption or transport, and thus play a role in mediating various biotic and abiotic stresses and developmental processes.

\subsection{Plant Phytohormone Signal Transduction and Lateral Root Formation Affect High $\mathrm{K}^{+}$Efficiency}

Lateral root (LR), as an important component of root system, is very important for absorbing water and nutrients and for adapting to soil environments $[18,20]$. Lateral root number (LRN) can be used as a morphological index to describe potassium absorption efficiency $[17,19]$. In the present study, LRN was positively correlated with KIUE, DW and total K content, and more LRs were found in HKE type Line 20. Based on these results, exploring the regulatory mechanism of root development, especially lateral root differentiation might be of great significance in improving $\mathrm{K}$ use efficiency of vegetable soybean.

Plant hormones play important roles in the regulation of root architecture formation [59-61]. According to the KEGG enrichment results under the LK condition, DEGs were significantly enriched in the "Plant hormone signal transduction" pathway In the present study. Among them, most genes were enriched in auxin signal transduction. Auxin has been widely reported as the main positive regulator, which regulates all stages of lateral root formation $[21,58,62,63]$. The present study also demonstrated the specific role of auxin in lateral root development of vegetable soybean. In Arabidopsis, periodic gene activities in the oscillation zone (covers the basal meristem and elongation zone) are at least partially correlated with auxin signaling, constituting an early step in positioning new LRs. This process relies on the AUX1 gene expression, which encodes an auxin influx carrier member that facilitates auxin transport [64]. The auxin signal captured by TIR1/AFBs accelerated the degradation of Aux/IAA proteins, typified by IAA14/SLR, IAA3/SHY2, IAA19/MSG2, and IAA28, thereby derepressing the function of ARF7 and ARF19 as transcriptional activators [65]. ARF7 and ARF19 activated the transcription of downstream target LBD genes, including LBD16, LBD18, and LBD29 [21]. LBDs also probably regulated lateral root formation by activating the down-stream EXPANSIN genes expression [20,63].

Integrated previous findings in Arabidopsis with our results [21,59,63], we develop a predicted auxin signaling cascade model for lateral root initiation. As shown in Figure 7, the AUX1 homologous gene Glyma02g42290 is higher expressed in Line 20. Two Aux/IAA family genes (Glyma13g22750 and Glyma20g35270) are repressed under low K condition which might derepress the expression of Glyma16g02650 (belong to ARFs family). Furthermore, the downstream LBD gene Glyma05g08870 is up-regulated under both low K and normal K conditions. All of those processes ultimately stimulate high expression of EXPANSIN genes in high K efficiency type Line 20, especially Glyma01g35070 and Glyma01g41330. This hypothesis may provide an important reference for vegetable soybean to improve potassium uptake efficiency by regulating lateral root formation. 


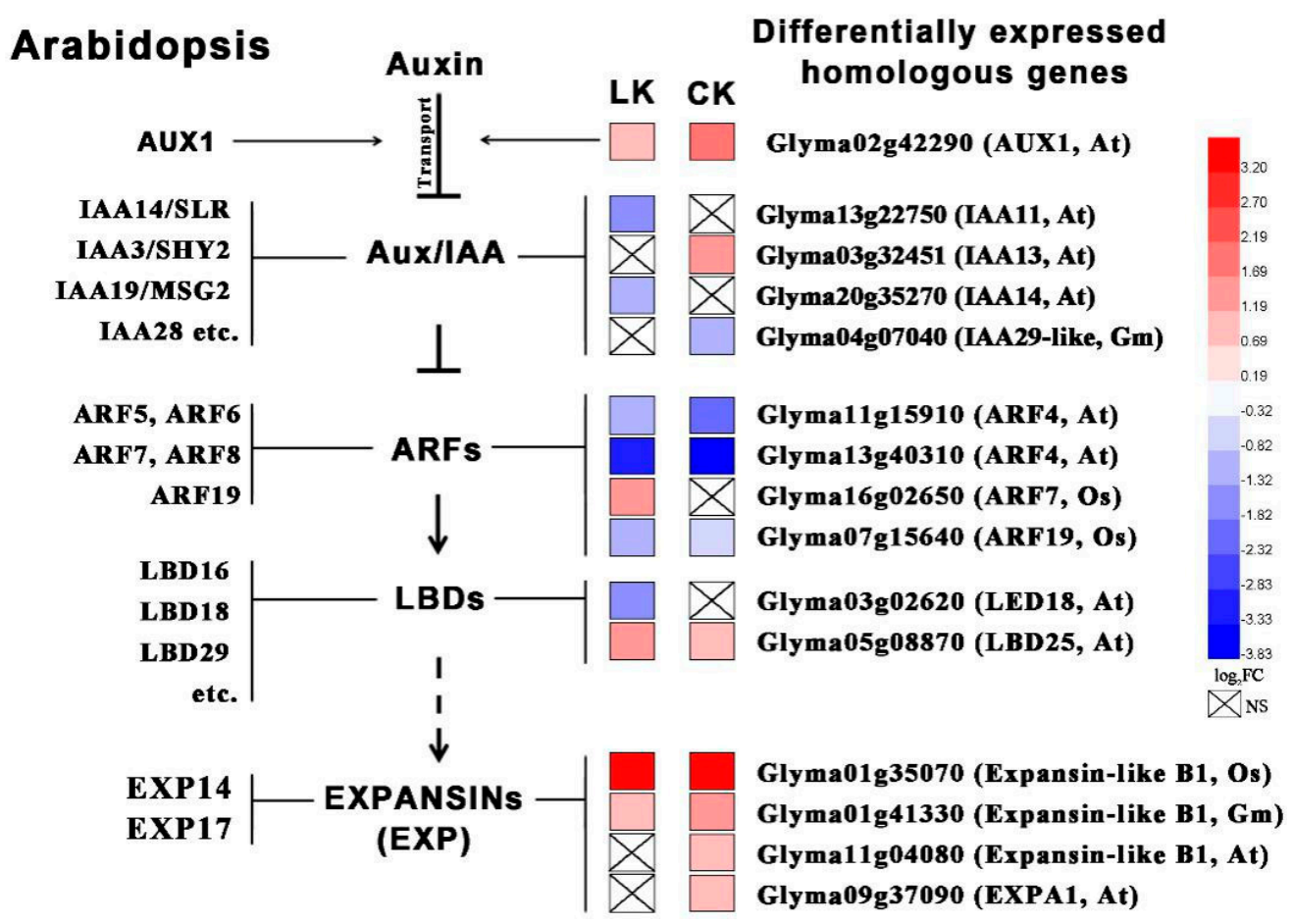

Figure 7. Predicted auxin signaling cascade model for lateral root initiation in vegetable soybean.

In addition to auxin, abscisic acid (ABA), ethylene, gibberellin (GA), jasmonic acid (JA) and cytokinin (CTK), also play regulatory roles in lateral root formation $[40,61,66,67]$. Previous investigations demonstrated that ethylene is an inhibitor to lateral root initiation $[18,60]$. In the present study, nineteen ethylene-responsive transcription factors (ERFs) were induced under the CK condition, but only three ERFs were differentially expressed and two of them were repressed under the LK condition. This suggests that low potassium stress in Line 20 may inhibit ethylene signaling to some extent. Additionally, a CTR1 (Glyma06g10241) gene was repressed and an EIN4 (Glyma03g41220) gene was induced in Line 20 . CTR1 is a downstream gene that is positively regulated by ETR $[60,68,69]$. The EIN4 gene encodes an ethylene receptor and belongs to ETR family, which is located on the endoplasmic reticulum and controls the output of ethylene signal in the form of negative feedback $[68,69]$. Therefore, the low ethylene signal transduction in Line 20 might have a positive impact on lateral root formation.

ABA signaling is mediated by a group of receptors known as the PYR1/PYL/RCAR family, while PYL8 is required for the recovery of lateral growth [61]. In the present study, one PYL1 gene (Glyma01g12970) was found repressed and one PYL9 (Glyma16g02910) was induced in Line 20 under the LK and CK conditions. A differentially expressed SnRK2 homologous gene (Glyma01g41260), which was highly expressed in Line 20 was also identified. Usually, under stress condition, ABA can inhibit lateral root initiation by activating SnRK2 protein kinases [61]. ABRE-binding protein (AREB)/ABRE-binding factor $(\mathrm{ABF})$ transcription factors (TFs), regulate $\mathrm{ABRE}-\mathrm{dependent} \mathrm{gene} \mathrm{expression} \mathrm{[70].} \mathrm{The} \mathrm{present}$ study identified two ABF genes (Glyma06g47220 and Glyma05g25200) and one KEG gene (Glyma13g26470, involved in $\mathrm{ABF}$ degradation) differentially expressed under the LK condition. In addition, some other genes responded to abscisic acid were also identified. Overall, these DEGs involved in ABA signal transduction might have realistic roles in regulating $\mathrm{K}$ efficiency, but whether these genes affect the initiation and development of lateral roots remains further investigation.

GA signal transduction also takes part in lateral root formation through interactions with auxin and other hormones [71]. GA2OX family genes are demonstrated being related to GA catabolic process, and overexpression of StGA2ox1 gene increases the tolerance to abiotic stress in transgenic potato plants (Solanum tuberosum L.) [72]. The present study found that three GA2OX family genes were up-regulated in Line 20 under the CK condition, whereas a GA2OX1 was (Glyma15g10070) down-regulated under the LK condition. GA-deficient (35S:PcGA20x1) and GA-insensitive (35S:rgl1) transgenic Populus exhibited 
increased lateral root proliferation and elongation [71]. Therefore, the down-regulated GA2OX1 gene might also contribute to lateral root formation. Furthermore, DELLAs are core transcriptional negative regulators of GA signaling. Increasing amounts of data showed that DELLAs are core cross-talk nodes for interactions of several plant hormones, such as GA, auxin, ethylene, ABA, brassinosteroid, salicylic acid and jasmonate [66]. A DELLA protein RGL1-like (Glyma15g15110) gene was induced in Line 20 under both LK and CK conditions, which may play certain roles in the interaction among plant hormones.

CTK has been shown to inhibit the initiation and elongation of lateral roots [73]. Fewer genes related to CTK were differentially expressed in this study, especially under the LK condition. Interestingly; however, Glyma06g24300, a gene involved in the cytokinin-activated signaling pathway (GO: 0009736), was only expressed in Line 7 . This may be an important candidate gene affecting K-efficiency genotypes.

JA might be one of the potent hormonal factors, other than auxin, involved in promoting LR formation [59,67]. JAR1 encodes the enzyme responsible for the conjugation of JA to amino acids, i.e., isoleucine and valine. Among these conjugates, JA-Ile is considered to be an important compound in the JA signaling pathway [74,75]. Interestingly, the homologous gene of JAR1 (Glyma06g37401) showed an opposite expression pattern under two potassium concentrations, namely significantly up-regulated under the LK condition and significantly down-regulated under the CK condition. Therefore, low K concentration stimulated the expression of JAR1 in Line 20. Allene oxide synthase (AOS) genes are involved in jasmonic acid biosynthesis [75]. The present study also identified an AOS1 (Glyma04g03740) gene down-regulated in Line 20 under both LK and CK conditions. This implies that the in situ synthesis intensity of JA in roots may not be strong. However, the enhancement trend of the JA signal in Line 20 through the significantly up-regulated expression of JAR1 under the LK condition may have important implications in regulating the development of HKE roots under low potassium conditions.

Additionally, the present study also identified some candidate genes which might be involved in root formation or development. These candidate genes are the SCARECROW transcription factor genes of GRAS family related to radial root growth (Goh et al., 2016); a XTH24 gene, responsible for cell division and expansion during radish taproot thickening process [24]; the ANR1 MADS-box gene, identified as a key regulator of lateral root growth in response to signals from external nitrate $\left(\mathrm{NO}_{3}{ }^{-}\right)$[37]; and a homologous gene from DGK family. All these genes require further analysis.

\section{Conclusions}

Based on the present investigation, HKE vegetable soybean Line 20 has a higher potassium accumulation, lower potassium sensitivity, and stronger ability in converting unit potassium into more dry matter, which ensures a high potassium uptake and use efficiency. Meanwhile, low K stress increases the total root length of the HKE genotype, and the LRN in HKE genotype is significantly higher than that of the LKE genotype, which dramatically influences the total root length and increases the spatial distribution of roots as well. More lateral roots increase the contact area between roots and $\mathrm{K}^{+}$, thus accelerating potassium absorption.

The auxin signal associated with other hormone signals would be an important mechanism affecting lateral root formation of HKE genotype. The two K channel genes (TPK1 and AKT1) and a HAK5 potassium transporter highly expressed in the HKE genotype may also play major roles in high-efficiency potassium absorption. Individually up-regulated genes in HKE genotype are significantly enriched in transport-related GO terms, which may ensure efficient transport of nutrients under low $\mathrm{K}$ stress. While genes related to response to stimulus, response to stress and defense response GO terms are significantly down-regulated in HKE genotype. The down-regulation may keep energy for better root formation and nutrients absorption. 
Supplementary Materials: The following are available online at http://www.mdpi.com/2073-4395/10/11/1796/s1, Figure S1: Gene Ontology annotation analysis of DEGs, Figure S2: Differentially expressed transcript factors between two genotypes at CK and LK conditions, Table S1: GO enrichment analysis of individually up-regulated DEGs at LK condition, Table S2: GO enrichment analysis of individually up-regulated DEGs at CK condition, Table S3: GO and KEGG enrichment analysis of individually down-regulated DEGs at CK condition, Table S4: GO enrichment analysis of co-up-regulated DEGs, Table S5: GO enrichment analysis of co-down-regulated DEGs, Table S6: DEGs enriched in transport-related GO terms at LK condition, Table S7: Auxin-related genes differentially expressed between two $\mathrm{K}$ efficiency types at normal $\mathrm{K}^{+}$and low $\mathrm{K}^{+}$conditions. Table S8: Ethylene-related genes differentially expressed between two $\mathrm{K}$ efficiency types at normal $\mathrm{K}^{+}$and low $\mathrm{K}^{+}$conditions. Table S9: Jasmonic acid-related genes differentially expressed between two $\mathrm{K}$ efficiency types at normal $\mathrm{K}^{+}$and low $\mathrm{K}^{+}$conditions. Table S10: Cytokinin-related genes differentially expressed between two $\mathrm{K}$ efficiency types at normal $\mathrm{K}^{+}$and low $\mathrm{K}^{+}$conditions. Table S11: Abscisic acid-related genes differentially expressed between two K efficiency types at normal $\mathrm{K}^{+}$and low $\mathrm{K}^{+}$conditions. Table S12: Gibberellin-related genes differentially expressed between two K efficiency types at normal $\mathrm{K}^{+}$and low $\mathrm{K}^{+}$conditions.

Author Contributions: Conceptualization: C.L., Q.Z. and X.L.; formal analysis: C.L. and B.T.; data curation: C.L., X.W. and Y.L.; writing: C.L. and X.L.; funding acquisition: Q.Z. All authors have read and agreed to the published version of the manuscript.

Funding: This paper is a part of the projects funded by National Natural Science Foundation of China (grant No. 41977096) and Strategic Priority Research Program of the Chinese Academy of Sciences (XDA24030403-3).

Conflicts of Interest: The authors declare that there is no conflict of interest.

\section{References}

1. Zhu, D.; Lu, J.; Cong, R.; Ren, T.; Zhang, W.; Li, X. Potassium management effects on quantity/intensity relationship of soil potassium under rice-oilseed rape rotation system. Arch. Agron. Soil Sci. 2019, 66, 1274-1287. [CrossRef]

2. Rengel, Z.; Damon, P.M. Crops and genotypes differ in efficiency of potassium uptake and use. Physiol. Plant. 2008, 133, 624-636. [CrossRef]

3. Pettigrew, W.T. Potassium influences on yield and quality production for maize, wheat, soybean and cotton. Physiol. Plant. 2008, 133, 670-681. [CrossRef]

4. Liu, C.; Tu, B.; Li, Y.; Tian, B.; Zhang, Q.; Liu, X.; Herbert, S.J. Potassium application affects key enzyme activities of sucrose metabolism during seed filling in vegetable soybean. Crop. Sci. 2017, 57, 2707-2717. [CrossRef]

5. Liu, C.; Wang, X.; Tu, B.; Li, Y.; Liu, X.; Zhang, Q.; Herbert, S.J. Dry matter partitioning and K distribution of vegetable soybean genotypes with higher potassium efficiency. Arch. Agron. Soil Sci. 2019, 66, 717-729. [CrossRef]

6. Liu, C.; Tu, B.; Wang, X.; Jin, J.; Li, Y.; Zhang, Q.; Liu, X.; Ma, B. Potassium translocation combined with specific root uptake is responsible for the high potassium efficiency in vegetable soybean. Crop. Pasture Sci. 2019, 70, 516-525. [CrossRef]

7. Fan, M.; Huang, Y.; Zhong, Y.; Kong, Q.; Xie, J.; Niu, M.; Xu, Y.; Bie, Z. Comparative transcriptome profiling of potassium starvation responsiveness in two contrasting watermelon genotypes. Planta 2013, 239, 397-410. [CrossRef]

8. Gierth, M.; Mäser, P. Potassium transporters in plants-Involvement in $\mathrm{K}^{+}$acquisition, redistribution and homeostasis. FEBS Lett. 2007, 581, 2348-2356. [CrossRef]

9. Cuin, T.A.; Dreyer, I.; Michard, E. The role of potassium channels in Arabidopsis thaliana long distance electrical signalling: AKT2 modulates tissue excitability while GORK shapes action potentials. Int. J. Mol. Sci. 2018, 19, 926. [CrossRef]

10. Ullah, H.; Datta, A. Root system response of selected lowland Thai rice varieties as affected by cultivation method and potassium rate under alternate wetting and drying irrigation. Arch. Agron. Soil Sci. 2018, 64, 2045-2059. [CrossRef]

11. Sharma, T.; Dreyer, I.; Riedelsberger, J. The role of $\mathrm{K}^{+}$channels in uptake and redistribution of potassium in the model plant Arabidopsis thaliana. Front. Plant Sci. 2013, 4, 224. [CrossRef]

12. Gomez-Porras, J.L.; Riaño-Pachón, D.M.; Benito, B.; Eharo, R.; Esklodowski, K.; Rodríguez-Navarro, A.; Dreyer, I. Phylogenetic analysis of $\mathrm{K}^{+}$transporters in bryophytes, lycophytes, and flowering plants indicates a specialization of vascular plants. Front. Plant Sci. 2012, 3, 167. [CrossRef] 
13. Rubio, F.; Nieves-Cordones, M.; Aleman, F.; Martinez, V. Relative contribution of AtHAK5 and AtAKT1 to $\mathrm{K}^{+}$uptake in the high-affinity range of concentrations. Physiol. Plant. 2008, 134, 598-608. [CrossRef]

14. Pyo, Y.J.; Gierth, M.; Schroeder, J.I.; Cho, M.H. High-affinity $\mathrm{K}^{+}$transport in Arabidopsis: AtHAK5 and AKT1 are vital for seedling establishment and postgermination growth under low-potassium conditions. Plant Physiol. 2010, 153, 863-875. [CrossRef]

15. Caballero, F.; Botella, M.A.; Rubio, L.; Fernández, J.A.; Martínez, V.; Rubio, F. A Ca ${ }^{2+}$-sensitive system mediates low-affinity $\mathrm{K}^{+}$uptake in the absence of AKT1 in Arabidopsis plants. Plant Cell Physiol. 2012, 53, 2047-2059. [CrossRef]

16. Gaymard, F.; Pilot, G.; Lacombe, B.; Bouchez, D.; Bruneau, D.; Boucherez, J.; Michaux-Ferrière, N.; Thibaud, J.-B.; Sentenac, H. Identification and disruption of a plant shaker-like outward channel involved in $\mathrm{K}^{+}$release into the Xylem Sap. Cell 1998, 94, 647-655. [CrossRef]

17. Volder, A.; Smart, D.R.; Bloom, A.J.; Eissenstat, D.M. Rapid decline in nitrate uptake and respiration with age in fine lateral roots of grape: Implications for root efficiency and competitive effectiveness. New Phytol. 2004, 165, 493-502. [CrossRef]

18. Ivanchenko, M.G.; Muday, G.K.; Dubrovsky, J.G. Ethylene-auxin interactions regulate lateral root initiation and emergence in Arabidopsis thaliana. Plant J. 2008, 55, 335-347. [CrossRef]

19. Zhang, Z.; Yang, F.; Li, B.; Eneji, A.E.; Li, J.; Duan, L.; Wang, B.; Li, Z.; Tian, X. Coronatine-induced lateral-root formation in cotton (Gossypium hirsutum) seedlings under potassium-sufficient and -deficient conditions in relation to auxin. J. Plant Nutr. Soil Sci. 2009, 172, 435-444. [CrossRef]

20. Kim, J.; Lee, H.W. Direct activation of EXPANSIN14 by LBD18 in the gene regulatory network of lateral root formation in Arabidopsis. Plant Signal. Behav. 2013, 8, e22979. [CrossRef]

21. Du, Y.; Scheres, B. Lateral root formation and the multiple roles of auxin. J. Exp. Bot. 2017, 69, $155-167$. [CrossRef]

22. Xuan, W.; Band, L.R.; Kumpf, R.P.; Van Damme, D.; Parizot, B.; De Rop, G.; Opdenacker, D.; Möller, B.; Skorzinski, N.; Njo, M.F.; et al. Cyclic programmed cell death stimulates hormone signaling and root development in Arabidopsis. Science 2016, 351, 384-387. [CrossRef]

23. Chen, W.J.; Zhu, T. Networks of transcription factors with roles in environmental stress response. Trends Plant Sci. 2004, 9, 591-596. [CrossRef]

24. Xie, Y.; Xu, L.; Wang, Y.; Fan, L.; Chen, Y.; Tang, M.; Luo, X.; Liu, L. Comparative proteomic analysis provides insight into a complex regulatory network of taproot formation in radish (Raphanus sativus L.). Hortic. Res. 2018, 5, 51. [CrossRef]

25. Xu, J.; Li, H.-D.; Chen, L.-Q.; Wang, Y.; Liu, L.-L.; He, L.; Wu, W.-H. A protein kinase, interacting with two calcineurin B-like proteins, regulates K+ transporter AKT1 in Arabidopsis. Cell 2006, 125, 1347-1360. [CrossRef]

26. Wang, C.; Chen, H.; Hao, Q.; Sha, A.; Shan, Z.; Chen, L.; Zhou, R.; Zhi, H.; Zhou, X. Transcript Profile of the Response of Two Soybean Genotypes to Potassium Deficiency. PLoS ONE 2012, 7, e39856. [CrossRef]

27. Wang, J.-D.; Hou, P.; Zhu, G.P.; Dong, Y.; Hui, Z.; Ma, H.; Xu, X.J.; Nin, Y.; Ai, Y.; Zhang, Y.-C. Potassium partitioning and redistribution as a function of K-use efficiency under $\mathrm{K}$ deficiency in sweet potato (Ipomoea batatas L.). Field Crop. Res. 2017, 211, 147-154. [CrossRef]

28. Armengaud, P.; Breitling, R.; Amtmann, A. The Potassium-Dependent Transcriptome of Arabidopsis Reveals a Prominent Role of Jasmonic Acid in Nutrient Signaling. Plant Physiol. 2004, 136, 2556-2576. [CrossRef]

29. Hardoim, P.R.; De Carvalho, T.L.G.; Ballesteros, H.G.F.; Bellieny-Rabelo, D.; Rojas, C.A.; Venancio, T.M.; Ferreira, P.C.G.; Hemerly, A.S. Genome-wide transcriptome profiling provides insights into the responses of maize (Zea mays L.) to diazotrophic bacteria. Plant Soil 2019, 451, 121-143. [CrossRef]

30. Ning, Y.; Wang, Y.; Fang, Z.; Zhuang, M.; Zhang, Y.; Lv, H.; Liu, Y.; Li, Z.; Yang, L. Comparative transcriptome analysis of cabbage (Brassica oleracea var. capitata) infected by Plasmodiophora brassicae reveals drastic defense response at secondary infection stage. Plant Soil 2019, 443, 167-183. [CrossRef]

31. Ding, Y.-E.; Fan, Q.-F.; He, J.-D.; Wu, H.-H.; Zou, Y.-N.; Wu, Q.-S.; Kuča, K. Effects of mycorrhizas on physiological performance and root TIPs expression in trifoliate orange under salt stress. Arch. Agron. Soil Sci. 2019, 66, 182-192. [CrossRef] 
32. Schiessl, S.; Quezada-Martinez, D.; Orantes-Bonilla, M.; Snowdon, R.J. Transcriptomics reveal high regulatory diversity of drought tolerance strategies in a biennial oil crop. Plant Sci. 2020, 297, 110515. [CrossRef] [PubMed]

33. Wang, H.; Wang, Z.; Zhang, M.; Jia, B.; Heng, W.; Ye, Z.; Zhu, L.; Xu, X. Transcriptome sequencing analysis of two different genotypes of Asian pear reveals potential drought stress genes. Tree Genet. Genomes 2018, 14, 40. [CrossRef]

34. Shen, C.; Wang, J.; Shi, X.; Kang, Y.; Xie, C.; Peng, L.; Dong, C.; Shen, Q.; Xu, Y. Transcriptome Analysis of Differentially Expressed Genes Induced by Low and High Potassium Levels Provides Insight into Fruit Sugar Metabolism of Pear. Front. Plant Sci. 2017, 8, 938. [CrossRef]

35. Huang, Y.; Fang, R.; Li, Y.; Liu, X.; Wang, G.; Yin, K.; Jin, J.; Herbert, S.J. Warming and elevated CO2 alter the transcriptomic response of maize (Zea mays L.) at the silking stage. Sci. Rep. 2019, 9, 1-9. [CrossRef]

36. Pfaffl, M.W. A new mathematical model for relative quantification in real-time RT-PCR. Nucleic Acids Res. 2001, 29, e45. [CrossRef]

37. Gan, Y.B.; Filleur, S.; Rahman, A.; Gotensparre, S.; Forde, B. Nutritional regulation of ANR1 and other root-expressed MADS-box genes in Arabidopsis thaliana. Planta 2005, 222, 730. [CrossRef]

38. López-Bucio, J.; Cruz-Ramírez, A.; Herrera-Estrella, L. The role of nutrient availability in regulating root architecture. Curr. Opin. Plant Biol. 2003, 6, 280-287. [CrossRef]

39. Gerard, F.; Blitz-Frayret, C.; Hinsinger, P.; Pagès, L. Modelling the interactions between root system architecture, root functions and reactive transport processes in soil. Plant Soil 2016, 413, 161-180. [CrossRef]

40. Zhao, X.-H.; Yu, H.-Q.; Wen, J.; Wang, X.; Du, Q.; Wang, J.; Wang, Q. Response of root morphology, physiology and endogenous hormones in maize (Zea mays L.) to potassium deficiency. J. Integr. Agric. 2016, 15, 785-794. [CrossRef]

41. Sun, H.; Li, J.; Song, W.; Tao, J.; Huang, S.; Chen, S.; Hou, M.; Xu, G.; Zhang, Y. Nitric oxide generated by nitrate reductase increases nitrogen uptake capacity by inducing lateral root formation and inorganic nitrogen uptake under partial nitrate nutrition in rice. J. Exp. Bot. 2015, 66, 2449-2459. [CrossRef] [PubMed]

42. Moreno-Risueno, M.A.; Van Norman, J.M.; Moreno, A.; Zhang, J.; Ahnert, S.E.; Benfey, P.N. Oscillating gene expression determines competence for periodic arabidopsis root branching. Science 2010, 329, 1306-1311. [CrossRef] [PubMed]

43. Song, W.-J.; Liu, S.-J.; Meng, L.; Xue, R.; Wang, C.-D.; Liu, G.-L.; Dong, C.-X.; Wang, S.-S.; Dong, J.-X.; Zhang, Y.-L. Potassium deficiency inhibits lateral root development in tobacco seedlings by changing auxin distribution. Plant Soil. 2015, 396, 163-173. [CrossRef]

44. Singh, K.B. Transcription factors in plant defense and stress responses. Curr. Opin. Plant Biol. 2002, 5, 430-436. [CrossRef]

45. Shiu, S.-H.; Shih, M.-C.; Li, W.-H. Transcription factor families have much higher expansion rates in plants than in animals. Plant Physiol. 2005, 139, 18-26. [CrossRef]

46. Li, L.; Gao, W.; Peng, Q.; Zhou, B.; Kong, Q.; Ying, Y.; Shou, H. Two soybean bHLH factors regulate response to iron deficiency. J. Integr. Plant Biol. 2018, 60, 608-622. [CrossRef]

47. Takada, S.; Hibara, K.; Ishida, T.; Tasaka, M. The CUP-SHAPED COTYLEDON1 gene of Arabidopsis regulates shoot apical meristem formation. Development 2001, 128, 1127-1135.

48. Hibara, K.-I.; Takada, S.; Tasaka, M. CUC1 gene activates the expression of SAM-related genes to induce adventitious shoot formation. Plant J. 2003, 36, 687-696. [CrossRef]

49. Hao, Y.-J.; Wei, W.; Song, Q.-X.; Chen, H.-W.; Zhang, Y.-Q.; Wang, F.; Zou, H.-F.; Lei, G.; Tian, A.-G.; Zhang, W.; et al. Soybean NAC transcription factors promote abiotic stress tolerance and lateral root formation in transgenic plants. Plant J. 2011, 68, 302-313. [CrossRef]

50. Meng, Q.; Zhang, C.; Gai, J.; Yu, D. Molecular cloning, sequence characterization and tissue-specific expression of six NAC-like genes in soybean (Glycine max (L.) Merr.). J. Plant Physiol. 2007, 164, 1002-1012. [CrossRef]

51. Ivashikina, N.; Becker, D.; Ache, P.; Meyerhoff, O.; Felle, H.H.; Hedrich, R. $\mathrm{K}^{+}$channel profile and electrical properties of Arabidopsis root hairs. FEBS Lett. 2001, 508, 463-469. [CrossRef]

52. Isayenkov, S.; Maathuis, F.J.M. Arabidopsis thalianavacuolar TPK channels form functional $\mathrm{K}^{+}$uptake pathways inEscherichia coli. Plant Signal. Behav. 2013, 8, e24665. [CrossRef] [PubMed] 
53. Ahn, S.J.; Shin, R.; Schachtman, D.P. Expression of KT/KUP genes in arabidopsis and the role of root hairs in K+ uptake. Plant Physiol. 2004, 134, 1135-1145. [CrossRef]

54. Osakabe, Y.; Arinaga, N.; Umezawa, T.; Katsura, S.; Nagamachi, K.; Tanaka, H.; Ohiraki, H.; Yamada, K.; Seo, S.-U.; Abo, M.; et al. Osmotic stress responses and plant growth controlled by potassium transporters in Arabidopsis. Plant Cell 2013, 25, 609-624. [CrossRef] [PubMed]

55. Ragel, P.; Ródenas, R.; García-Martín, E.; Andrés, Z.; Villalta, I.; Nieves-Cordones, M.; Rivero, R.M.; Martínez, V.; Pardo, J.M.; Quintero, F.J.; et al. CIPK23 regulates HAK5-mediated high-affinity K ${ }^{+}$uptake in Arabidopsis roots. Plant Physiol. 2015, 169, 2863-2873. [CrossRef] [PubMed]

56. Hirsch, R.E.; Lewis, B.D.; Spalding, E.P.; Sussman, M.R. A role for the AKT1 potassium channel in plant nutrition. Science 1998, 280, 918-921. [CrossRef]

57. Li, J.; Long, Y.; Qi, G.-N.; Xu, Z.-J.; Wu, W.-H.; Wang, Y. The Os-AKT1 channel is critical for $\mathrm{K}^{+}$uptake in rice roots and is modulated by the rice CBL1-CIPK23 complex. Plant Cell 2014, 26, 3387-3402. [CrossRef]

58. KChin, K.; Moeder, W.; Yoshioka, K. Biological roles of cyclic-nucleotide-gated ion channels in plants: What we know and don't know about this 20 member ion channel family. Botany 2009, 87, 668-677.

59. Wang, S.; Ichii, M.; Taketa, S.; Xu, L.; Xia, K.; Zhou, X. Lateral root formation in rice (Oryza sativa): Promotion effect of jasmonic acid. J. Plant Physiol. 2002, 159, 827-832. [CrossRef]

60. Negi, S.; Ivanchenko, M.G.; Muday, G.K. Ethylene regulates lateral root formation and auxin transport inArabidopsis thaliana. Plant J. 2008, 55, 175-187. [CrossRef]

61. Zhao, Y.; Xing, L.; Wang, X.; Hou, Y.J.; Gao, J.; Wang, P.; Duan, C.G.; Zhu, X.; Zhu, J.K. The ABA receptor PYL8 promotes lateral root growth by enhancing MYB77-dependent transcription of auxin-responsive genes. Science signaling. Sci. Signal 2014, 7, ra53. [CrossRef] [PubMed]

62. Casimiro, I.; Beeckman, T.; Graham, N.; Bhalerao, R.; Zhang, H.; Casero, P.; Sandberg, G.; Bennett, M.J. Dissecting Arabidopsis lateral root development. Trends Plant Sci. 2003, 8, 165-171. [CrossRef]

63. Lee, H.W.; Kim, M.-J.; Kim, N.Y.; Lee, S.H.; Kim, J. LBD18 acts as a transcriptional activator that directly binds to theEXPANSIN14promoter in promoting lateral root emergence of Arabidopsis. Plant J. 2012, 73, 212-224. [CrossRef]

64. Bennett, M.J.; Marchant, A.; Green, H.G.; May, S.T.; Ward, S.P.; Millner, P.A.; Walker, A.R.; Schulz, B.; Feldmann, K.A. Arabidopsis AUX1 gene: A permease-like regulator of root gravitropism. Science 1996, 273, 948-950. [CrossRef]

65. Okushima, Y.; Fukaki, H.; Onoda, M.; Theologis, A.; Tasaka, M. ARF7 and ARF19 regulate lateral root formation via direct activation of LBD/ASL genes in Arabidopsis. Plant Cell 2007, 19, 118-130. [CrossRef]

66. Guo, W.; Cong, Y.; Hussain, N.; Wang, Y.; Liu, Z.; Jiang, L.; Liang, Z.; Chen, K.-M. The remodeling of seedling development in response to long-term magnesium toxicity and regulation by aba-della signaling in Arabidopsis. Plant Cell Physiol. 2014, 55, 1713-1726. [CrossRef] [PubMed]

67. Cai, X.-T.; Xu, P.; Zhao, P.-X.; Liu, R.; Yu, L.-H.; Xiang, C.-B. Arabidopsis ERF109 mediates cross-talk between jasmonic acid and auxin biosynthesis during lateral root formation. Nat. Commun. 2014, 5, 5833. [CrossRef] [PubMed]

68. Hua, J.; Sakai, H.; Nourizadeh, S.; Chen, Q.G.; Bleecker, A.B.; Ecker, J.R.; Meyerowitz, E.M. EIN4 and ERS2 are members of the putative ethylene receptor gene family in Arabidopsis. Plant Cell 1998, 10, 1321. [CrossRef]

69. Ireland, H.S.; Guillén, F.; Bowen, J.; Tacken, E.; Putterill, J.; Schaffer, R.J.; Johnston, J.W. Mining the apple genome reveals a family of nine ethylene receptor genes. Postharvest Biol. Technol. 2012, 72, 42-46. [CrossRef]

70. Nakashima, K.; Yamaguchi-Shinozaki, K. ABA signaling in stress-response and seed development. Plant Cell Rep. 2013, 32, 959-970. [CrossRef]

71. Gou, J.; Strauss, S.H.; Tsai, C.J.; Fang, K.; Chen, Y.; Jiang, X.; Busov, V.B. Gibberellins regulate lateral root formation in Populus through interactions with auxin and other hormones. Plant Cell 2010, 22, 623-639. [CrossRef] [PubMed]

72. Shi, J.; Wang, J.; Wang, N.; Zhou, H.; Xu, Q.; Yan, G. Overexpression of StGA2ox1 gene increases the tolerance to abiotic stress in transgenic potato (Solanum tuberosum L.) plants. Appl. Biochem. Biotechnol. 2018, 187, 1204-1219. [CrossRef]

73. Laplaze, L.; Benkova, E.; Casimiro, I.; Maes, L.; Vanneste, S.; Swarup, R.; Weijers, D.; Calvo, V.; Parizot, B.; Herrera-Rodriguez, M.B.; et al. Cytokinins act directly on lateral root founder cells to inhibit root initiation. Plant Cell 2007, 19, 3889-3900. [CrossRef] [PubMed] 
74. Stenzel, I.; Otto, M.; Delker, C.; Kirmse, N.; Schmidt, D.; Miersch, O.; Hause, B.; Wasternack, C. ALLENE OXIDE CYCLASE (AOC) gene family members of Arabidopsis thaliana: Tissue- and organ-specific promoter activities and in vivo heteromerization. J. Exp. Bot. 2012, 63, 6125-6138. [CrossRef] [PubMed]

75. Pratiwi, P.; Tanaka, G.; Takahashi, T.; Xie, X.; Yoneyama, K.; Matsuura, H.; Takahashi, K. Identification of jasmonic acid and jasmonoyl-isoleucine, and characterization of AOS, AOC, OPR and JAR1 in the Model Lycophyte Selaginella moellendorffii. Plant Cell Physiol. 2017, 58, 789-801. [CrossRef] [PubMed]

Publisher's Note: MDPI stays neutral with regard to jurisdictional claims in published maps and institutional affiliations.

(C) 2020 by the authors. Licensee MDPI, Basel, Switzerland. This article is an open access article distributed under the terms and conditions of the Creative Commons Attribution (CC BY) license (http://creativecommons.org/licenses/by/4.0/). 